\title{
Nationalliteratur - ein Projekt der Moderne zwischen Mystifikation und politischer Integrationsrhetorik
}

\author{
Was ist Nation? Ein großer, ungejäteter \\ Garte voll Kraut und Unkraut.
}

J.G.Herder (1793)

$0 . \quad$ Vorbemerkung

1. Exposition: „Weltsprache" - „Weltliteratur" - „Nationalliteratur"

2. Gesetzmäßiger Gang von der „National-“ zur „Weltliteratur"?

3. Die Literaturnation - ein deutscher Tagtraum

4. Genese der „Nationalliteratur“ aus dem Geist des kulturellen Pluralismus

5. Die Geschichte der „Nationalliteratur" ist die „Familiengeschichte“ des Bildungsbürgertums

6. Literatur

\section{Vorbemerkung}

Der Begriff „Nationalliteratur“ weist in zwei Richtungen: auf die Literatur von einer und auf die Literatur für eine Nation. Die Last der Abstraktion macht das Wort ungefüge. Denn beide Elemente des Kompositums beschwören Einheitsvorstellungen, die nicht nur historischem Wandel unterworfen, sondern überhaupt mit der Vielfalt empirischer Erscheinungen nicht im Einklang sind. Man redet in solchen Fällen daher zutreffend von Ideen. Zwischen ihnen und der Realität herrscht jene Spannung, in deren Gravitationsfeld Aktionsprogramme bzw. Projekte entstehen, die - unter Vorspiegelung eines in Zukunft möglichen Versöhnungs- oder Ruhepunktes - den Energiebetrag erwähnter Spannung als Antriebsmoment nutzen. „Die Fakta sind nur die Resultate der Ideen“, schrieb Heine 1835 mit der Ungeduld dessen, der das, was sein soll, als seiend imaginiert. ${ }^{1}$ Das literarhistorische Projekt aber, in dem dieser Satz steht - die Romantische Schule -

1 Heine 1979, 216. 
zollt jener Spannung zwischen Ideen und ,Fakten` Tribut, die der Schriftsteller wie nur wenige seiner Zeit- und Leidensgenossen aus einem politischen Punkt zu kurieren suchte.

Wenn hier wie im folgenden die Idee der „Nationalliteratur" mit einem Projekt der Moderne zusammengedacht wird, so liefert dafür den Leitfaden die in den Quellen selbst enthaltene, auch wider besseres Wissen aufrechterhaltene Überzeugung, daß die literarische, nicht zuletzt die poetische Sprache mit den Ideen zugleich auch die Realität verändern kann. Von den Anfängen moderner nationaler Denkarten im 18. Jahrhundert bleibt dies bis weit in die Zeit der radikalen Nationalismen der Fels einer zählebigen Glaubenslehre, auf dem Nationbildung und literarische Bildung eine merkwürdige Ehe eingegangen sind, die im übrigen ganz zu Unrecht als unpolitische Mesalliance geschmäht wird. Unsere These lautet: Die von der imaginären „Nation" kommende Literatur, insbesondere ihre Poesie, war lange Zeit für die im Sinne einer bildungsbürgerlichen Elite entstehende "Nation" integraler Bestandteil ihres symbolischen Kapitals. Mit ihrer Hilfe sollte es gelingen, im Rahmen der seit dem Ende des 18. Jahrhunderts verstärkt einsetzenden sozialen Differenzierungskämpfe ein wichtiges, nach oben (Adel) wie nach unten (Volk) abgrenzendes, identitäts- und zugleich kohärenzstiftendes kulturelles Exklusivrecht durchzusetzen und zu behaupten. Der Rest ist Verfallsgeschichte.

\section{Exposition: „Weltsprache“ - „Weltliteratur“ - „Nationalliteratur"}

Die "Weltsprache" und lingua franca der modernen Poesie, schrieb Hans Magnus Enzensberger zu Beginn der 60er Jahre, verweigere sich den Standardisierungen und Beschränkungen der "Nationalliteratur". Was hier "Weltsprache" heißt, ist nicht im engen Sinn einer Einheitssprache zu verstehen, sondern berührt den Widerstand, den die Autoren moderner Poesie - so Enzensberger - gegen jede Art der Reglementierung aufbieten; das sei ihr Gemeinsames, während die Gedichte ihre Vitalität den lokalen Sprachen, der „Würde des Provinziellen“, verdankten. ${ }^{2}$ Partikulares und Universelles gehen in diesem Argument zusammen. Die Einzelsprache schließt die supranationale, ja globale Bedeutung der Texte nicht aus, vorausgesetzt sie reflektieren das, was Enzensberger "geschichtliche Erfahrungen“ nennt. Und die sprachlichen Äußerungen dieser Reflexion sind nicht jenem Gebot

2 Weltsprache der modernen Poesie. In: Enzensberger 1963, 20. 
der Verständlichkeit verpflichtet, die das geneigte Lesepublikum anmahnt, um den poetischen Widerspruch zu entschärfen.

Enzensbergers Poetik der Moderne entwirft Dichtung als eine Form sprachlicher Resistance im weitesten Sinn des Worts: Widerstand gegen politische Machtansprüche, gegen die Normen der offiziösen Sprache, gegen die Publikumserwartungen kulinarischen Konsums, aber auch gegen jene wissenschaftlich-pädagogischen Auslegungs- und Einordungsrituale, die unter der Flagge der Klassikerpflege segeln. ${ }^{3}$

Dieses Plädoyer für den sanften Einspruch der Weltpoesie gegen die bedrückende Trägheit von Machtstrukturen jeder Art, ein Einspruch, der den kommunikativen Lese-Erwartungen zuwiderläuft, wendet sich gegen das Ethos der professionellen und selbsternannten Verwalter der Nationalliteraturen, gegen die kulturfrommen Vermittler und unter diesen vor allem gegen die Literaturhistoriker, deren Beruf es ist, die Geschichte der Schrifttradition einer Nationalsprache zu erzählen, um auf diese Weise das Kultprestige des Kanons zu sichern. Enzensberger wußte, wogegen er protestierte. Er hatte im restaurativen Klima der 50er Jahre Germanistik studiert und mit einer Dissertation über einen Exponenten der Romantischen Schule, genauer: über Clemens Brentanos Poetik abgeschlossen. Wenige Jahre später erscheint das von ihm zusammengestellte und edierte Museum der modernen Poesie, die „wichtigste und folgenreichste Lyrikanthologie der deutschen Nachkriegsära" ${ }^{4}$ : für den Herausgeber und Lyriker der entscheidende publizistische Schritt aus der akademisch eingehegten National- in die zeitgenössische Weltliteratur - für die Experimentierlust der westdeutschen Poesieproduktion ein wichtiger Impuls. Das Publikum, das sich dem neuen Leseabenteuer widmen sollte, mußte sich der Herausgeber der Weltpoesie freilich erst schaffen; auch hier galt es nationale Beschränktheiten abzubauen.

Szenenwechsel: Zwanzig Jahre nach dem Erscheinen des „Museums“ veröffentlicht die Deutsche Akademie für Sprache und Dichtung in ihrem Jahrbuch eine Debatte über den Begriff der "Nationalliteratur", an der sich Literaturwissenschaftler und Schriftsteller aus den beiden Deutschland, aus Österreich und der Schweiz beteiligten. Die einzelnen Beiträge rufen Verwirrung hervor, denn sie suchen das in Frage stehende, eigentlich schon recht modrige Etikett zu verabschieden und kommen dennoch nicht davon los. Der DDR-Staat hatte 1956 auf dem Vierten Schriftstellerkongreß eine zweite "deutsche Nationalliteratur" zum Programm erhoben, die sich - die Zentrale in Moskau ließ grüßen - an den Normen einer „Internationale des

3 "Auch Pindar und Goethe sind dunkel, nur ist diese ,Unverständlichkeit" vergessen, verdrängt, unschädlich gemacht worden. [...] Widerspruch ist auch ihre Poesie“. Enzensberger 1963, 25.

4 Harald Hartung, Poesie im Prozeß. In: Luftfracht 1991, 9. 
sozialistischen Realismus“ auszurichten hatte. Nicht Sprachzugehörigkeit, Bildungsideologie oder kulturelle Grenzen sollten über das bestimmen, was der einen oder andern „Nationalliteratur“ zuzurechnen ist, sondern das Parteibüro. Eine zum Scheitern verurteilte Literaturpolitik, die einem Credo literarischer Erziehung nahestand, das bürgerlicher Herkunft war und einst im 19. Jahrhundert eine Blütezeit genossen hatte. ${ }^{5}$ Vielleicht erinnerte sich dessen das westdeutsche Akademie-Direktorium, als es das unzeitgemäße Problem nochmals auf die Agenda setzte.

Vor dem Hintergrund dieses vom Jahr 1980 aus gesehen recht sonderbaren Hantierens mit der "Nationalliteratur" lag es nicht gerade nahe, zum wiederholten Male den Mythos von der Identität zwischen Nation und Sprache zu bemühen. Das Auseinanderklauben sozio- und dialektaler Idiotismen in den Literaturen Österreichs, der Schweiz sowie der beiden deutschen Staaten konnte denn auch dem problematisierten Schlagwort, wie die Dokumentation der Akademie-Debatte belegt, nicht zu logischer Würde verhelfen. "Gibt es eine schweizerische Nationalliteratur?" fragte sich der Schriftsteller Adolf Muschg vor dem Akademie-Publikum und antwortete mit dem sarkastischen Hinweis auf die „schweizerische Not", sich gegenüber dem Fremden, nicht zuletzt gegenüber dem „Kanton Deutschland“ zu behaupten, vor allem wenn es darum ginge, eine fragwürdige "natürliche Identität“ der Schweiz zur Schau zu stellen (Jahrbuch 1980, 67). War es Mitte der 50er Jahre noch ein nobles Geschäft, die Quintessenz schweizerischen "Wesens" in der Mehrsprachigkeit und in den "internationalen Zügen" der "Nation" zu suchen", so findet der selbstkritische Geist ein Vierteljahrhundert später das Gemeinsame in der Schwierigkeit, für ein homogenes, eine Nationalsprache sprechendes Lesepublikum zu schreiben: „Die trennende Mehrsprachigkeit läßt sich nicht aufheben; es gibt keine Schweizer Nationalliteratur".7

Die Neigung, als Kern der eigenen, der „nationalen“ Kultur etwas Gemeinsames zu setzen, das alles Trennende überwindet, findet sich dann und wann wohl in allen modernen Gesellschaften; selbst die Negation des Gesuchten kann dafür herhalten: „Unsre Nationalität ist, keine haben zu

Martin Gregor-Dellin, Die vergebliche Teilung. In: Jahrbuch 1980, 23 ff. In dem zit. Jahrbuch der Deutschen Akademie für Sprache und Dichtung finden sich u. a. - sprechendes Beispiel für das bedenkenlose Nebeneinander liberaler und reaktionärer Autoren in den Annalen der Akademie - zwei Gedichte von Otto Heuschele. Dieser noch in den 60er und 70er Jahren offiziell dekorierte staatstragende Autor gehörte nicht zuletzt mit seinem 1943 veröffentlichten Buch Geist und Nation zu denen, die mithilfe der, soldatischen' Literatur die Nation auf Vordermann bringen wollten. Zur Biographie Heuscheles vgl. Claudia Albert, Die erfolgreichen Vermittler: Studienräte, Publizisten, Editoren. In: Barner/König 1996, $249 \mathrm{ff}$.

6 Gibt es eine schweizerische Nationalliteratur? [1954] In: Ernst 1963, $93 \mathrm{ff}$.

7 Hanno Helbling, Es gibt (k)eine Schweizer Nationalliteratur. In: Jahrbuch 1980, 58. 
wollen" .8 Die Frage ist nur, ob dieser Mechanismus à tout prix auch auf die Literaturen kulturell heterogener Kollektive, zu denen ich alle modernen Nationalstaaten rechne, angewendet werden muß, die ja doch nur eine, häufig sogar sehr elitäre Fracht auf dem Strom der Gesamtkultur bilden. Für die österreichischen Teilnehmer der Akademie-Debatte war das übrigens kein Thema, da sie - wenn auch mit verlegenem Unterton - in der kanonisierten Literatur ihres Landes das Hausgespenst des „habsburgischen $\mathrm{My}$ thos" als das Bindende ausmachten. ${ }^{9}$ Die Frage nach dem Publikum einer so halbherzig wie ideologisch definierten, wenn auch nicht geradezu verteidigten österreichischen "Nationalliteratur" wurde indessen nicht gestellt, obwohl es doch auf der Hand liegt, daß die thematisierte Sache ohne Antwort auf diese Frage ein törichtes Luftgespinst bleibt.

Zieht ein unbefangener Anhänger des problematischen Kompositums "Nationalliteratur" die Summe aus der skizzierten Debatte des Jahres 80, so mag er folgern, es sei doch trotz allem verständlichen Hader aus pragmatischen Gründen durchaus realistisch und daher vernünftig, in Entsprechung zu den politisch bzw. soziologisch abgrenzbaren Bildungseliten in der Schweiz, in Österreich etc. von verschiedenen „Nationalliteraturen " deutscher Sprache zu reden. Das „Nationale“ könne dann aus der dubiosen Verklammerung mit der Sprache gelöst und auf solche kulturell-historischen Idiosynkrasien des kollektiven Bewußtseins bezogen werden, deren Spuren der ,eigenen' Literatur ein unverwechselbares Gesicht gegeben haben und weiterhin geben. - Was aber sagt die Gegenseite? Nun, das gebrannte Kind, der historisch sensibilisierte, selbstkritisch denkende Deutsche wird pragmatische Argumente nicht gelten lassen. Hat er doch den durch einen „größenwahnsinnig gewordenen Nationalismus“ (B. Allemann) verschuldeten Genozid vor Augen, der das Erbe nationalliterarischer Bildungstraditionen, mit dem sich die Mörder brüsteten, in ein böses Zwielicht gerückt hat. Das geschändete Traditionsbewußtsein durch verzeihendes Abstrafen zu reinigen, ist nicht möglich. Bleibt also nur die verbale Antipolitik, die auf „Nationalsprache" mit „Weltsprache" und auf „Nationalliteratur" mit "Weltliteratur" antwortet. ${ }^{10}$

Wer so energisch für „Weltliteratur" eintritt, beruft sich in der Regel auf jenen Archipoeta der deutschen „Nationalliteratur", der schon zu Beginn

8 Menzel $1828(1981,44)$, eine ähnliche Aussage Lessings (Hamburgische Dramaturgie, 101.-104. Stück) aus dem Jahre 1768 zuspitzend.

9 Hilde Spiel, „der österreicher küßt die zerschmetterte hand“. Über eine österreichische Nationalliteratur. In: Jahrbuch 1980, $34 \mathrm{ff}$. Klaus Hoffer, „In Wien ein Teller mit Sprüngen". In: Jahrbuch 1980, $43 \mathrm{ff}$.

10 „Es gibt nur Weltliteratur“, konstatierte der Germanist Beda Allemann unter Berufung auf Goethe (Jahrbuch 1980, 15), ,in nach Weltgegend notwendig verschiedenen Sprachen, Literatur nämlich, die aus der Region heraus Welt eröffnet und verständlich macht." 
des Jabrhunderts der Nationalismen die antizyklische Parole ausgegeben hatte: „Nationalliteratur will jetzt nicht viel sagen, die Epoche der Weltliteratur ist an der Zeit".

Die Arznei der „Weltliteratur", die diesen Namen im Grunde nicht verdient, da sie sich vornehmlich aus den nationalen Literaturen Europas zusammensetzte, ist bald nach dem Zweiten Weltkrieg der Literaturwissenschaft als Gegengift gegen die in der Deutschen Philologie unter Hitler übliche Volkstümelei verschrieben worden. ${ }^{12}$ Der in diesem Fach geübte vorauseilende Gehorsam gegenüber dem Regime wurde sofort nach der $\mathrm{Ka}$ pitulation mit Erfolg jahrzehntelang verdrängt. Und zwar mit dem Effekt einer Begriffsverwirrung, da die Germanistik des Dritten Reichs den vorstaatlichen Ausdruck „Volk“ (auch „volkstümlich“, „völkisch“) oder die in der zweiten Hälfte des 19. Jahrhunderts rassistisch aufgeladene Wendung vom "deutschen Wesen“ dem Schlagwort „Nationalliteratur" vorzog. ${ }^{13}$

"Weltliteratur": In seiner ozeanischen Weite erscheint dieser Begriff besonders schwer faßbar. Der Ausdruck „Nationalliteratur“, kehren wir um des Vergleiches willen nochmals zur oben skizzierten Diskussion zurück, läßt sich immerhin auf mindestens zwei begriffliche Verwendungsweisen reduzieren:

- Im ersten Fall steht der Ausdruck für die Literatur der Schriftsteller $e i$ ner Sprache, unabhängig von ihrer Staatszugehörigkeit; was schon deshalb vertretbar ist, weil - historisch gesehen - Staat und Nation bis 1871 nicht zur Deckung kamen.

- Im zweiten Fall gilt als Kriterium literarischer Nationalität der Fundus inhaltlicher Gemeinsamkeiten, sei dieser nun von mythopoietischer, sozialpsychologischer (früher sagte man: „charakterlicher"), ideologischer, politischer oder mentaler Art.

Der Begriff der „Weltliteratur“ erscheint demgegenüber so libertär wie das Pendant „Weltbürgertum“ und erinnert an Literaturauffassungen, die sich über kulturelle und sprachliche Differenzierungen in der literarischen Urteilsbildung hinwegsetzen möchten.

11 Johann Peter Eckermann, Gespräche mit Goethe in den letzten Jahren seines Lebens. Hrsg. v. R. Otto. 4. Aufl. Berlin, Weimar 1987, 198.

12 Strich 1946; Curtius 1948.

13 Vgl. den Sprachgebrauch in der von G. Fricke u.a. 1941 hrsg., ausdrücklich als ideologische Kriegsteilnahme konzipierten fünfbändigen Sammlung Von deutscher Art in Sprache und Dichtung. Von wenigen Ausnahmen abgesehen, haben die in diesen Bänden vertretenen Autoren nach 1945 als Germanistikprofessoren weitergearbeitet. 


\section{Gesetzmäßiger Gang von der „National-“ zur „Weltliteratur"?}

Schon der Singular „Literatur“ ist zwar für kommunikative Zwecke bequem, enthält zugleich aber einen Stolpermechanismus, da er ein Allgemeines (eine Systemstruktur, eine Norm?) suggeriert, das jene konkrete Vielfalt überwölbt, die zutreffend nur der Plural „Literaturen“ beschreibt. Wieviel mehr Anlaß zu Mißverständnissen liefert dann aber erst das singularische Kompositum „Nationalliteratur“! Goethes Prognose von 1827, die eine "Epoche der Weltliteratur" voraussah, setzte die Existenz "nationaler" bzw. - wie der längst Klassischgesprochene damals schrieb - "nationeller“ Einzelliteraturen voraus. Läßt man sich von Goethes Sprachgebrauch leiten, der dem Usus des späten 18. Jahrhunderts nahestand, so vertritt „das Nationelle" ein Sammelsurium lokaler Besonderheiten innerhalb einer einzigen Muttersprachenliteratur, steht vielleicht dem Landespatriotismus nahe und zeigt insofern noch Verwandtschaft mit dem, worauf Enzensbergers und Allemanns territoriale Begriffe des „Provinziellen“ und „Regionalen" anspielen. ${ }^{14}$ Entscheidend aber ist: Als „Nationalliteratur" gilt ausschließlich das Kanonisierte; die populären Lesestoffe, die - jene früher übliche Gleichsetzung von „Nation" und „Volk“ vorausgesetzt - das Vergnügen der Masse bilden, wurden bestenfalls von den glücklosen Erfindern der „Volks“- oder „Nationalbücher“ ernst genommen, die das Volk der Leser in ihrem Sinne erziehen wollten. ${ }^{15}$

Die "nationale“ oder "nationelle“ Literatur beruht stets auf einer für Nichteingeweihte kaum nachvollziehbaren Wertung und exklusiven Auswahl; und das nicht nur in jenem berühmten literarhistorischen 7. Buch von Goethes Dichtung und Wabrheit, dem zahlreiche deutsche Literarhistoriker des 19. Jahrhunderts ihr selbständiges Urteil geopfert haben. Die Idee einer kommenden Weltliteratur aber verhält sich zu der durchs „Nationelle“ geprägten Hochliteratur keineswegs exklusiv oder gar antinomisch. Beide Begriffe stehen vielmehr in engster Korrelation und sind Erfindungen ein und derselben Emanzipationsbewegung, nämlich der historischen Aufklärungsepoche. Denn „Weltliteratur" ist in Goethes Denken ein Er-

14 Goethe trennt in Dichtung und Wabrbeit noch nicht scharf zwischen "nationell" und "provinziell“ und kann insofern auch vom "vollkommene(n) norddeutsche(n) Nationalgehalt" eines dramatischen Werks sprechen. In: Goethe, BA 13, 1972, 288 u. 305.

15 Hinrich C. Seeba, Nationalbücher. Zur Kanonisierung nationaler Bildungsmuster in der frühen Germanistik. In: Fohrmann/Voßkamp 1991, 57-71. Die Identität von klassischer Hoch- und Nationalliteratur bildete das Rückgrat der Literaturgeschichten des 19. Jahrhunderts. Zu den wenigen Stimmen, die der Populärliteratur mehr Rechte im "großen Publikum“ einräumten, gehörte die Gustav Freytags; vgl. seine 1866 veröff. Rezension von Julian Schmidts Geschichte der deutschen Literatur in: Freytag 1901, $31 \mathrm{ff}$. 
wartungsbegriff und bezeichnet eine Form der inter-nationalen Kommunikation, auf der nicht nur die kulturelle Toleranz im Sinne des Gewährenlassens aufbauen soll, sondern aus der auch alle daran Beteiligten Gewinne der verschiedensten Art werden ziehen können. ${ }^{16}$

Dieses Projekt der Weltliteratur ist nicht nur im Sinn einer abstrakten Anerkennungspolitik entworfen worden. ${ }^{17}$ Goethe begreift vielmehr die zunehmenden Verflechtungen zwischen Verkehrs-, Kommunikations- und Handelsdichte im supranationalen Raum seiner Zeit als eine Chance, zugleich mit der Verständigung zwischen den Gesellschaften, „die Differenzen, die innerhalb einer Nation obwalten, durch Ansicht und Urtheil der übrigen" auszugleichen. ${ }^{18}$ Wenn in diesem Zusammenhang überhaupt der Begriff, soziokultureller Identität ' angebracht ist, dann hätte der Archipoeta mit dieser Bemerkung, denkt man an den möglichen Verlauf der Identitätsbildung, ins Schwarze getroffen. Sind ,Identitäten ' doch niemals in der oben von Muschg ironisch zitierten Weise "natürlich" gegeben, sondern von kontingenten Bedingungen abhängig, also stets wandelbar und bilden sich allenfalls im Austausch und Blickwechsel mit Andern heraus. So daß eine autonome Selbstsetzung der ,Identität' als ganz und gar illusionär zu betrachten ist. Der Blick von außen - „Ansicht und Urtheil der übrigen“ ist, insbesondere in der Selbstwahrnehmung des von diesem Urteil Betroffenen, eine mögliche Bedingung für die Homogenisierung der „Differenzen" im Innern.

Bezieht man diese Einsichten in den Aufbau von ,Identitäten' zunächst allein auf die Literatur einer Nation, so wäre festzuhalten, daß diese ihre Eigentümlichkeiten nur im Vergleich oder in der Konkurrenz mit bzw. Gegnerschaft $\mathrm{zu}$ andern Nationalliteraturen ausbilden wird und daß eine Beschreibung dieser Verhältnisse sowohl die Außen- wie die Innenperspektive umfassen muß. Nicht zufällig hat sich daher die Vergleichende Literaturwissenschaft (Komparatistik) schon in ihren Anfängen des Projekts „Weltliteratur" mit besonderer Wärme angenommen. Gewiß, sie hat die Bücher, die nach ihrem Dafürhalten zum weltliterarischen Kanon gehören, nach Maßgabe europäischer Ästhetiknormen bewertet, ausgewählt sowie kano-

16 „Diese Zeitschriften“, so kommentierte Goethe 1828 einige schottische Journale, „wie sie sich nach und nach ein größeres Publikum gewinnen, werden zu einer gehofften allgemeinen Weltliteratur auf das wirksamste beitragen; nur wiederholen wir, daß nicht die Rede sein könne, die Nationen sollen übereindenken, sondern sie sollen nur einander gewahr werden, sich begreifen und, wenn sie sich wechselseitig nicht lieben mögen, sich einander wenigstens dulden lernen." Goethe [Edinburgh Reviews. 1828], BA 18, 1972, 416.

17 Wenige Jahre zuvor heißt es in Maximen und Reflexionen: „Toleranz sollte eigentlich nur eine vorübergehende Gesinnung sein: sie muß zur Anerkennung führen. Dulden heißt beleidigen". (Goethe a.a.O., 610).

18 Brief an Sulpiz Boisserée v. 12. 10. 1827. Zit. nach Hendrik Birus, Goethes Idee der Weltliteratur. Eine historische Vergegenwärtigung. In: Schmeling 1995, 14. 
nisiert; überhaupt hat sie das Konstrukt der homogenen Nationalliteraturen Europas niemals konsequent in Frage gestellt. Und dennoch, ihr Vorzug gegenüber einer borniert oder gar chauvinistisch aufs Eigene, das heißt aber auch: auf die Nation als zu formierendes Publikum sich konzentrierenden Nationalphilologie ist nicht zu leugnen. Ein Vorzug, der darüber hinaus eine ökonomische Seite hat, da die Komparatistik mit der Entstehung eines internationalen Buchmarktes und dito Publikums Hand in Hand ging. Sie hat Zug um Zug auch die Tätigkeit des Übersetzens als einen entscheidenden Faktor im transnationalen Literaturaustausch begriffen und inzwischen als ein ergiebiges Forschungsfeld ausgebaut, das der Entzauberung chauvinistischer Nationalklischees schöne Dienste leisten kann.

Von dem hier angedeuteten Zusammenhang zwischen Weltwirtschaft und literarischer Kommunikation hatte der Kosmopolit Goethe durchaus eine Ahnung. Zitierfähigen Ausdruck jedoch fand dieser Zusammenhang knapp 20 Jahre nach seinen Worten in einem berühmten, rasch in alle Weltsprachen übersetzten politischen Text, in dem die ökonomische Expansion auf kapitalistischer Grundlage als Antriebsmoment nicht nur für globale Produktionsweisen und weltweiten Güterfluß, sondern auch für die transnationale literarische Kommunikation - Stichwort „Weltliteratur" - erkannt worden ist. ${ }^{19}$

Diese Einsichten des Kommunistischen Manifests zielten ähnlich wie Goethes Äußerungen auf die Zukunft. Die Autoren dachten die längst in Gang gekommenen Prozesse der Industrialisierung und des Kolonialismus zuende, beharrten aber - in recht undialektischer Manier - auf der Analogie zwischen Weltmarkt und Weltliteratur. Hatte Goethe sich noch pragmatisch an die literarische Kommunikation zwischen Nationen gehalten und insofern den kosmopolitischen Klang des Ausdrucks "Weltliteratur" relativiert, so verweisen nun Marx \& Engels, belehrt durch die Diagnose des grenzenlos sich ausdehnenden Kapitalismus, auf eine Entwicklung, die heute unter dem Schlagwort der „Globalisierung“ die Gemüter erregt. Zunächst aber hat sich die Geschichte an die Prognose der Kapitalismuskriti-

19 „Die Bourgeoisie hat durch ihre Exploitation des Weltmarktes die Produktion und Konsumtion aller Länder kosmopolitisch gestaltet. [...] Die uralten nationalen Industrien [...] werden verdrängt durch neue Industrien, deren Einführung eine Lebensfrage für alle zivilisierten Nationen wird, durch Industrien, die nicht mehr einheimische Rohstoffe, sondern den entlegensten Zonen angehörige Rohstoffe verarbeiten und deren Fabrikate nicht nur im Lande selbst, sondern in allen Weltteilen zugleich verbraucht werden. [...] An die Stelle der alten lokalen und nationalen Selbstgenügsamkeit und Abgeschlossenheit tritt ein allseitiger Verkehr, eine allseitige Abhängigkeit der Nationen voneinander. Und wie in der industriellen, so auch in der geistigen Produktion. Die geistigen Erzeugnisse der einzelnen Nationen werden Gemeingut. Die nationale Einseitigkeit und Beschränktheit wird mehr und mehr unmöglich, und aus den vielen nationalen und lokalen Literaturen bildet sich eine Weltliteratur". Manifest der kommunistischen Partei [1848]. In: Marx 1964, 529. 
ker nicht gehalten, sondern die Mißgeburt radikaler und militanter Nationalismen begünstigt. Es liegt nahe, die Gründe dafür nicht nur im Kampf um die besten Plätze auf dem Weltmarkt zu suchen, sondern auch in der Reaktion auf die vom europäischen Imperialismus ausgehende, nach innen wie nach außen wirkende Bedrohung lokaler Traditionen. Marx' \& Engels' Erwartung an die kosmopolitische Parallelentwicklung von Industrie, Handel und Literatur schien im übrigen stillschweigend vorauszusetzen, daß sich die Sprachgrenzen, die als Kommunikationsbarrieren für eine solche Entwicklung anzusehen sind, in einer Art grenzenlosem Übersetzungskommerz von selbst auflösten. Für die Literatur politischen, philosophischen, wissenschaftlichen Gehalts - mit einem Wort: für die Aufklärungsliteratur - wurde das bei gleichzeitig wachsender Alphabetisierung sicher als Gewinn verbucht.

Es ist anzunehmen, daß die Autoren des Kommunistischen Manifests den Literaturbegriff in einem viel weiteren Sinne verwendet haben, als das Goethes Absicht war, da sie wie jeder Intellektuelle, der dem Traum von der Transsubstantiation des Wortes in die Tat nachhängt, auf dem Papier den Erfolg der Verwandlung vorwegnehmen mußten. Der Vergleich zwischen den zeitlich benachbarten Positionen - hie Goethe, da Marx \& Engels - macht ferner auf eine Zweideutigkeit im formalen Gebrauch des Literaturbegriffs aufmerksam, die die Semantik beider Konzepte - „National-“ wie „Weltliteratur“ - berührt: Goethes Verständnis steht für eine (Nationalautoren verbindende) Form der literarischen Kommunikation, das von Marx \& Engels für eine Form der literarischen Produktion, deren Erscheinungsbild mit den Distributionsgesetzen der kapitalistischen Handelswirtschaft übereinstimmt. In beiden Fällen erscheint das Projekt „Weltliteratur" im Kontext einer zugleich aufgeklärten und elitären Ideenpolitik. Denn die kulturellen Bedingungen, die ein solches Projekt erst möglich machen, Alphabetisierung und Existenz einer verfeinerten Schriftkultur, waren um die Mitte des 19. Jahrhunderts selbst in den aufstrebenden Industriegesellschaften keineswegs klassenübergreifend vorhanden. ${ }^{20}$ Die internationalen bzw. kosmopolitischen Zukunftsbilder, die Goethe, Marx \& Engels entwarfen, entsprachen daher der Selbsteinschätzung und wohl auch dem Wunschdenken einer literarischen Elite, die mit der Macht des geschriebenen Wortes, die ihr als symbolisches Kapital zu Gebote stand, den Anspruch auf eine - sei es mäßigend, sei es radikalisierend eingreifende - übernationale Wirkung verbunden hat.

Für unsere Fragestellung bemerkenswert ist die mit den skizzierten Positionen verschwisterte geschichtsphilosophische Idee, die partikularen nationalen Einheiten würden nach und nach zu einer universalistisch sich ausdehnenden literarischen Ökumene zusammenwachsen. Eine Idee, die

20 Engelsing 1973, $90 \mathrm{ff}$. 
nicht allein im Reich der Literatur und Gelehrsamkeit herumgeisterte. Sie hat vielmehr auch die frühen Theoretiker der Nationalökonomie von Friedrich List (1841) bis Gustav Cohn (1885) fasziniert. Das Werden der Nationen wurde insofern - wie die Entwicklung ihrer Ökonomien und Literaturen - als eine notwendige Etappe der dem großen Ziel der Universal- oder Weltgesellschaft sich nähernden Evolution aufgefaßt. In diesem Prozeß, der von den kleineren zu immer umfassenderen und komplexeren sozialen Einheiten (Gruppe - Familie - Stamm - Region - Nation - Welt) führen sollte, besaßen Wissenschaften und Künste eine Schlüsselrolle. ${ }^{21}$

\section{Die Literaturnation - ein deutscher Tagtraum}

Friedrich List hatte 1841 die politische Ökonomie an die Epochenkonstruktionen der Geschichtswissenschaft verwiesen, den „freien Handel mit weiter vorgerückten Nationen“ als einen ersten Schritt aus der „Barbarei“ begrüßt und diesen zur Vorbedingung für eine später eintretende liberale Epoche der „freien Konkurrenz“ erklärt. ${ }^{22}$ Dieses Gedankenspiel im Feld der Ökonomie hat seine genauen Vorbilder im Geisterreich der literarischen Kultur. $\mathrm{Zu}$ den „weiter vorgerückten Nationen“ rechnete List und zählten schon die deutschen, aber auch manche französischen Intellektuellen des 18. Jahrhunderts den Inselstaat England. In den freien, nicht zuletzt geistigen Handel mit der englischen Gesellschaft und ihrer Kultur einzutreten, bedeutete für die deutschen Literaten nicht nur, in die Koalition der gegen die Macht der französischen Nachbarkultur kämpfende Partei einzurücken, sondern war auch ein Gang zu den Quellen nationalen Denkens. Denn England galt und gilt als die Wiege der liberalen NationalIdee. ${ }^{23}$ Es kann an dieser Stelle nicht darum gehen, die intensive Rezeption englischer Autoren und die Auseinandersetzung deutschsprachiger Schriftsteller im 18. Jahrhundert mit dieser Literatur - von den Texten der sensualistisch-empiristischen Philosophie über die Wirtschaftstheorien der schottischen Physiokraten bis zu den Moral Weeklies der Addison \& Steele und den Klassikern der epischen und dramatischen Poesie - nachzuzeichnen. Nur soviel: Entscheidend für die Suche nach einer eigenständigen „National-Dichtung" und "-Literatur" war für die Deutsch schreibenden Autoren der Zeit die Konsolidierung des europäischen Literaturkanons, in dem ne-

21 Hobsbawm 1996, $51 \mathrm{ff}$.

22 Zit. nach Bernd Schönemann, Volk, Nation. In: Geschichtliche Grundbegriffe, Bd. 7. 1992, 342.

23 Vgl. das instruktive Kapitel „God's Firstborn: England“. In: Greenfeld 1993, $27 \mathrm{ff}$. 
ben Homer, Vergil, Dante, Tasso, Ariost, Cervantes auch die Engländer Milton und Shakespeare und - hält man sich an den einflußreichen KanonArchitekten Johann Jacob Bodmer - neben diesen bald auch Wolfram von Eschenbach sowie das Nibelungenlied die ersten Plätze einnahmen. ${ }^{24} 1780$, in dem denkwürdigen Jahr, in dem Friedrich II. von Preußen seine berühmte - notabene! - französisch verfaßte Invektive gegen die deutschsprachige Literatur schleuderte ${ }^{25}$, schrieb der schweizerische Gelehrte Leonhard Meister, ein Schüler Bodmers, über den deutsch-englischen Literaturkommerz, die „teutsche Bühne“ borge bei den Briten, weil in deren Theaterliteratur sich der Mensch „in seiner rohen, ungekünstelten Natur“ zeige. ${ }^{26}$

Meister argumentiert hier in Übereinstimmung mit der Mehrheit seiner Deutsch schreibenden Zeitgenossen. Der Topos einer sich zu sich selbst bekennenden „ungekünstelten“, gar „rohen Natur“ enthält den Kern der Integrationsrhetorik, die im literarischen Universum jener Zeit, das des kaum entwirrbaren Geflechts der eng gezogenen Grenzen unzähliger politischer Herrschaftsterritorien spottete, gang und gäbe war. Vom Theater erwartete man viel: Seit dem ersten Drittel des Jahrhunderts befand sich die schreibende Elite auf der Jagd nach einem „Nationaltheater", obwohl, wie Lessing 1768 bemerkte: „wir Deutsche noch keine Nation sind", und sich beeilte hinzuzufügen, er "rede nicht von der politischen Verfassung, sondern bloß von dem sittlichen Charakter." 27 Verfassung oder Charakter, Politik oder Gesinnung - diese Unterscheidung ist zu jener Zeit längst schon Gemeinplatz. Sie belegt treffend den allgemein bekannten Tatbestand, daß selbst den kosmopolitischen Köpfen keine Alternative zur Nationalisierung einfallen wollte, auch wenn diese allein auf den diesseits der politischen Machtbeteiligung verlaufenden ungewissen Weg einer kollektiven Sittenschule und Charakterformierung angewiesen schien. Lessings Sarkasmus galt der Illusion, die Bühne, würde sie nur erst einmal so recht eingedeutscht, könne ein Nationalbewußtsein wecken und langfristig stabilisieren. $\mathrm{Da}$ diese Illusion sich als relativ langlebig erwies und von Schiller in den $80 \mathrm{er}$ Jahren mit großem sprachlichem Pathos erneuert wurde, ist u.a. mit dem außerordentlichen Prestige der theatralischen Repräsentationsformen in der als schlechte Konvention und überfällige Herrschaftsbastion be-

24 Vgl. das Kapitel „Johann Jacob Bodmer: Der Umriß eines neuen Kanons“. In: Weltliteratur 1982, $92 \mathrm{ff}$.

25 De la littérature allemande. Des défauts qu'on peut lui reprocher; quelles en sont les causes; et par quels moyens on peut les corriger. Berlin 1780.

26 „Vielleicht eben, weil keine Nation ist, in welcher man mehr Mensch seyn und sich in seiner rohen, ungekünstelten Natur zeigen darf als in der brittischen - vielleicht auch, weil diese mit der unsrigen am meisten sympathisiert, fing man an, die teutsche Bühne aus den Fundgruben der englischen zu bereichern". Meister 1780, II/100.

27 Lessing, 4. Bd., 1973, 698. 
kämpften höfischen Sozialordnung zu erklären. ${ }^{28}$ Funktionierte das Theater im Rahmen dieser Ordnung als ein exklusiver, auf das höfische Publikum bezogener Ort symbolischer Machtentfaltung und zugleich als ein Spiegel fürstlicher Selbstinszenierung, so war es nur konsequent, wenn bürgerliche Autoren dieses Medium in Besitz nehmen wollten, um mit seiner Hilfe nicht nur zu einem exklusiven Stand, sondern zur ganzen Nation, ja zur Menschheit zu reden, als deren wahre Repräsentanten sie sich selber verstanden. „Nationaltheater" hießen bald jene Bühnen in einigen größeren Städten, die deutschsprachige Dramen in ihr Repertoire aufnahmen und, unterstützt von aufgeklärten Adligen, Autoren und Stadtbürgern, das ins Werk setzen wollten, was Leonhard Meister (1780, II/106) „Veredlung des Nationalkarakters" nannte. ${ }^{29}$ Ein berühmter poetischer Reflex dieser zwischen Adelsconduite und Bürgertugend stehenden theatralischen Sittenschule findet sich in der Bildungsgeschichte, die Goethe in Wilhelm Meisters Lebrjabren erzählt.

Wo bürgerliche Reformbestrebungen die „Hoftheater“ erreichten, galt der Kampf jenen mit üppigen, fürstlich dotierten italienischen Opern und französischen Schauspielen wuchernden Spielplänen, die den ästhetischen Erwartungen der europäischen Adelskultur entgegenkamen. Unter den Propagandisten der Nationaltheater und der Nationaldichtung war jetzt aber die Rede von einem "Geschmack“ anderer Art. Was Meister die „rohe, ungekünstelte Natur" nannte, das hieß bei andern „Sprache des Herzens" und "der Empfindung“. Und diese als Medium gelingender oder scheiternder Selbsterkenntnis einem der Idee nach als egalitär eingeschätzten Publikum vorzuführen (sei es auf der Bühne des Nationaltheaters oder im intimen Zirkel des Vorlesekabinetts), kam jener bürgerlich-nationalen Geschmacksund Sprachbildung am nächsten, die sich im Kampf gegen die Traditionen der Adelskultur auf den scheinbar praxisfernen Kult der geschriebenen, allenfalls feierlich von Bühne oder Katheder herabtönenden Rede verließ. "Indem der Deutsche schreiben muß, um Professor zu werden," notierte 1781 selbstkritisch Justus Möser, „geht der Engländer zur See, um Erfahrungen zu sammeln. “30 Da Schreiben und Handeln wie Räsonnement und Machtausübung auseinanderfielen, träumten die Schreib- und Schriftex-

28 Schiller in seiner Mannheimer Rede Was kann eine gute stebende Schaubühne eigentlich wirken? aus dem Jahr 1784: „wenn wir es erlebten, eine Nationalbühne zu haben, so würden wir auch eine Nation" (Schiller 1959, 830).

29 Zur Theatergeschichte der Zeit vgl. Brauneck 1996, 701 ff. - Daß im Frühjahr 1919 die erste deutsche Republik im Nationaltheater der Klassikerhochburg Weimar gegründet wurde, war wohl kein Zufall.

30 Möser 1986, 83. 1844 lautet der Vergleich: „Fanzosen und Russen gehört das Land, I Das Meer gehört den Briten, / Wir aber besitzen im Luftreich des Traums / Die Herrschaft unbestritten“. Heinrich Heine, Deutschland - Ein Wintermärchen, Caput VII. 
perten von Machtwechseln auf dem langen Weg literarischer Einflußnahme.

Die Nationalbildung in Deutschland begann als ein säkulares Buchstabengewächs, Frucht einer tief verankerten Schriftgläubigkeit, deren protestantisch-pietistischer Nährboden oft genug beschrieben worden ist. Klopstocks Deutsche Gelehrtenrepublik von 1774 und Herders Entwurf Zum ersten patriotischen Institut für den Allgemeingeist von 1787 können sicher als wohlmeinende Reformprogramme dieser Richtung gelten, obwohl des ersteren Einfall, die Staatsverfassung auf eine Poetik zu gründen, schon von manchen Zeitgenossen als höherer Blödsinn belächelt wurde. Echtes Vertrauen aber in die bewegende, zugleich potentiell verändernde Kraft des geschriebenen Wortes brachten die genannten wie auch andere Autoren vorab jener Sprache der Empfindung entgegen, deren Bändigung durch die poetische Form Ton und Aussage bis ins Harmonische oder noch darüber hinaus ins Heilig-Erhabene zu steigern vermochte. ${ }^{31}$ Zweifellos ein wichtiger Beitrag zur Flexibilisierung der Rede und Erweiterung ihrer psychischen Expressivität. Wenn etwas jener „Vollkommenheit“ Ausdruck geben sollte, die Herder nicht nur „National“, sondern auch „Säkular" und „Individuell“" genannt hatte, dann war es die Sprache der neuen Poesie. ${ }^{32}$

Eine so elitäre Protesthaltung, die wenig später unter repressiveren politischen Bedingungen in Schillers Traum vom „ästhetischen Staat“ mündete, vermied den offenen Konflikt mit der Macht, um im relativen Schutzraum literarischer und gelehrter Publizistik Stellvertreterkämpfe auszufechten. Sie mußte oft nach Kants berühmtem Paradoxon handeln: „Räsonirt so viel ihr wollt, und worüber ihr wollt; nur gehorcht!“"33 Und sie gefiel sich bisweilen auch in andern Paradoxa, da sie mit größter sprachlicher Kunstfertigkeit das angeblich „Gekünstelte“ der französischen Hofkultur im Namen einer „Natürlichkeit“ bekämpfte, die - allem Erhabenheitspathos zum Trotz - mit jenen typisch mittelständischen Vorstellungen übereinstimmte, die im „redlichen Manne“ das neue, dem höfischen „Weltmann“ opponierende Gesellschaftsideal sehen wollte. ${ }^{34}$

31 Das gilt cum grano salis auch für Herders wirkungsästhetische, auf dem Bild(ungs)begriff aufbauende Konzeption der Historiographie, die er vor allem in Auch eine Philosopbie der Geschichte zur Bildung der Menschbeit (1774) begründet und mit seiner eigenen Schreibweise bekräftigt hat.

32 Herder, Auch eine Philosophie der Geschichte zur Bildung der Menschheit, 1774. In: SW V, 1891, 539.

33 Immanuel Kant, Beantwortung der Frage: Was ist Aufklärung? In: Berlinische Monatsschrift IV, 1784, 493.

34 „In jeder Provinz Deutschlands“, schrieb Herder 1793, „leben Männer, die ohne französische Eitelkeit, ohne englischen Glanz, gehorsam, oft leidend, Dinge tun, deren Anblick jedermann schönen und großen Mut einspräche, wenn sie bekannt wären. Denen vollends wünsche ich keinen Hof, keine Hauptstadt; einen Altar der Biedertreue wünsche ich ihnen, an dem sie sich mit Geist und Herzen versammeln. Er kann nur 
Anders als in Frankreich, so resümiert Norbert Elias ein Ergebnis seiner vergleichenden Studien, hat die deutsche Intelligenz jener Zeit den „Nationalcharakter" in den Eigenschaften des "mittelständischen Sozialcharakters" gesucht. ${ }^{35}$ Wenn es Ende der 70er Jahre hieß, die Schriftsteller lebten „mehr in dem Kabinet oder auf dem Lehrstul als in der Welt" und in „geistreiche(n) Cercle(n)" (Meister 1780, I/9; II/10f.), so stützt das den sozialhistorischen Befund: Die neue soziale Formation, die von einer kulturellen Reform im Zeichen der Nationwerdung träumte und - als „Bildungsbürgertum“ - ihre Gruppenzugehörigkeit in erster Linie über literarisch gesittete Kompetenzen definierte, war alles andere als ein Haufen rebellischer Staatsfeinde. Gehörten ihre Mitglieder doch zu jener reformwilligen Dienstleistungselite, die sich aus Verwaltungsbeamten, Theologen, Lehrern und Professoren zusammensetzte. ${ }^{36}$

Aber dem Beobachter um 1780 war auch klar, daß die „Veredlung des Nationalkarakters" mithilfe von Bühne und Büchern nicht nur eines langen Atems, sondern auch der Orientierung an großen anregenden Vorbildern bedurfte, die, da die eigene literarische Tradition kaum nachahmenswerte bzw. konkurrenzfähige Muster- und Meisterwerke enthielt, in fremden, meist an der kulturellen Peripherie liegenden Gärten aufzuspüren waren.

\section{Genese der „Nationalliteratur“ aus dem Geist des kulturellen Pluralismus}

Protestbewegungen, die sich gegen die Hegemonie des Zentrums richten, greifen dieses von der Peripherie aus an, eine verallgemeinerungsfähige Beobachtung, die nicht zuletzt für die moderne Konstruktion nationaler ,Identitäten ${ }^{6}$ gilt. ${ }^{37}$ Eine „Nationalliteratur“, die als Motor der Nationwer-

im Geist existieren, d.i. in Schriften [...]“. Herder BBH I,30. Volkstümelnde Autoren des frühen 19. Jahrhunderts haben den mittelständischen, als ,urdeutsch ' gefeierten Tugendkatalog weiter ausgemalt; vgl. z. B. Jahns weit verbreitete Schrift Deutsches Volkstum (1810), in der neben „Biederkeit" u.a. als deutsche Tugenden "Vollkraft", "Gradheit", „Redlichkeit" und "Gutmeinen" genannt werden. In: Jahn 1884, I, 155. „Seit man so viel von dieser Biederkeit redet," kommentiert wenig später Menzel ([1828] 1981, 27), „ist sie äußerst verdächtig geworden, ungefähr wie die deutsche Freiheit immer zweifelhafter wird, je mehr man sie im Munde führt".

35 Elias 1976, $36 \mathrm{ff}$. Vgl. auch die neuere, an Elias anknüpfende Untersuchung von Rudolf von Thadden, Aufbau nationaler Identität. Deutschland und Frankreich im Vergleich. In: Giesen 1991, 493-512.

36 Vierhaus 1987, $167 \mathrm{ff}$.

37 Shmuel Noah Eisenstadt, Die Konstruktion nationaler Identitäten in vergleichender Perspektive. In: Giesen 1991, 21-38. 
dung funktionieren soll, ist nicht nur auf eine einheitliche, weitgehend standardisierte Schriftsprache, sondern auch auf eine entsprechende Kompetenz des Lesepublikums angewiesen. Der Streit um die Normierung einer deutschen Hochsprache im 18. Jahrhundert war vor allem ein Streit über Gestalt und Verbreitung der Schrift- sowie Bildungssprache, im weitesten Sinne also über Literatur und mehr oder weniger offen übers Publikum. ${ }^{38}$ Die Nationwerdung in Gang zu bringen, schien den pädagogisch Berufenen der Zeit ohne die strenge Arbeit an einem nationalliterarischen Code und Erziehungsmodell gar nicht denkbar. Moderne Historiker haben diesen Zusammenhang immer wieder betont. ${ }^{39}$ Die Schulmeister der Nation sprachen von nichts anderm: angefangen mit Karl von Mosers Traktat Von dem deutschen Nationalgeist (1765) bis zu Fichtes Reden an die deutsche Nation (1807/08). Wenn hier und jetzt schon keine politische Einheit möglich schien, dann - so lautete die Überzeugung - war sie doch auf geistiger Ebene anzustreben, und diese Ebene war vor allem die der Schriftkultur; denn zwischen "Geist" und "Schrift" machte mancher namhafte Literaturexperte des 18. Jahrhunderts keinen Unterschied. ${ }^{40}$ Die Einheit der Nation war ein schriftsprachliches Bildungswerk, ihre erste, vorpolitische Stufe das „teilnehmende Publikum“. ${ }^{41}$ Noch 1828 schwärmte der einflußreiche Literaturkritiker Wolfgang Menzel von der ,geheimen Wahlverwandtschaft" des deutschen Nationalcharakters "mit den Büchern" und gestand "wahre Bildung" allein dem „Mittelstand" $\mathrm{zu} .{ }^{42}$

Kultur, Bildung, Literatur: Die Begriffe wurden in dieser Epoche zwar noch nicht überall trennscharf - sei es subjekt-, sei es objektbezogen - verwendet, brachten aber in mancherlei Verbindungen die schriftzentrierte Dynamik der mittelständischen kulturellen Mobilisierung zum Ausdruck. Wenn es einen „Nationalcharakter“ gab, dann - so hieß es 1773 in einem Buch über Nationalerziehung - war er im „gesitteten Mittelstand“ zu suchen; und dann hing, so der Schluß, von der „Bildung“ dieses Standes der „Zustand des Ganzen ab". Kaum fünfzig Jahre später war es ein Standardargument unter Historikern, daß sich „Teutschlands Nationalbildung in der Litteratur" vollzogen hatte und weiterhin vollzog. ${ }^{43}$ Die bewegende, stets offene

38 Gessinger 1980, $91 \mathrm{ff}$.

39 Vgl. z.B. Otto Dann, Begriffe und Typen des Nationalen in der frühen Neuzeit. In: Giesen 1991, 68. Umfangreiche Belegsammlung in Wehlers (I, 1987, 506 ff.) Kapitel mit der instruktiven Überschrift: „Die Anfänge des modernen deutschen Nationalismus als Reaktion auf Modernisierungskrisen, Revolution und Fremdherrschaft".

40 Herder BBH I, 30. Siehe oben S. 362 f.

41 Lothar Gall, Einheit. In: Geschichtliche Grundbegriffe, Bd. 2. 1975, 125.

42 Menzel 1981, 21 u. 40 f. An erster Stelle heißt es: „Die Literatur ist in der neuesten Zeit so sehr die glänzendste Erscheinung unsrer Nationalität geworden, daß wir diese eher aus jener erklären können als umgekehrt".

43 Resewitz, Die Nationalerziehung und zweckmäßige Einrichtung des öffentlichen Erziehungswesens (1773); zit. nach Vierhaus 1987, 514. Wachler 1818/19, II, 206. 
Frage war nur, mit welchem literarischen Futter dieser „Nationalcharakter“ hochgepäppelt und gestärkt werden sollte. "National-Charakter" - der zweite Teil des Kompositums legt die Assoziation nahe, es handle sich hier um das Ergebnis einer mehr oder weniger gewaltsamen Operation des Einzeichnens oder Einprägens individueller Spuren ins kollektive Bewußtsein. Eine fragwürdige metaphorische Übertragung individueller Bildungsprozesse auf eine Gruppe oder auf noch größere soziale Konstellationen, die in der Regel mit normativen Vorstellungen verbunden - der in der Gemeinschaft dominierenden Gruppe kulturelle Kohärenz- oder Homogenitätsbedürfnisse unterstellt. Aus diesem simplifizierenden Gesichtswinkel erscheint der "Nationalcharakter" als eine Ansammlung von stereotypen Eigenschaften, die um ihrer Positivierung willen gern auf gemeinsame Abstammungsfiktionen zurückgeführt wurden.

Eine dieser unter deutschen Intellektuellen beliebten Abstammungsgeschichten setzte mit Luthers Reformation und Übersetzungsarbeit ein. Zwei andere Abstammungsgeschichten, die nicht wie die Luthers aus dem Zentrum der protestantischen Kultur stammten, sondern gewissermaßen vom römisch-lateinischen Rand her importiert wurden, waren sehr viel älter und nach und nach zu gewichtigen Kolportagestories herangereift; die Rede ist vom Germanenlob des Tacitus und vom Sieg des Cheruskers Hermann über den Römer Varus, beides ergiebige Quellen für die Konstruktion nationaler Mythen in der Literatur und im Rahmen des populäreren Musiktheaters. ${ }^{44}$ Und dann gab es noch eine vierte solcher Geschichten, die dazu herhalten mußten, um eine ,heilige' Vergangenheit des „Nationalcharakters" $\mathrm{zu}$ erfinden, nämlich die von der innigen, sowohl linguistisch als auch kognitivistisch interpretierten Verwandtschaft zwischen Deutsch und klassischem Griechisch. ${ }^{45}$ Diese heterogenen Zutaten des Nationalcharakters wurden in vielfältiger Weise literarisch und/oder ideologisch-rhetorisch ausgebeutet und - je nach historischer Situation - mit mehr oder weniger chauvinistischen Spitzen gegen die Welt der Romania gewendet. Sie prätendierten - jede auf ihre Weise - Besonderheit und waren insgesamt etwas Besonderes, da sie der Fabrikation nationaler Gesinnung ein ziemlich buntes Gemisch aus griechischer Geistigkeit und germanischem Heroismus zumuteten. Wort und Tat sollten wohl auf der Grundlage dieser verwegenen Kumpanei wieder zusammenfinden. Betrachten wir zunächst kurz die griechische Seite, die der Rückübertragung Distinktion und dreifachen Prestigegewinn versprach:

44 Winfried Woesler, Construction littéraire et instrumentalisation des mythes nationaux Arminius et Jeanne d'Arc. In: Espagne/Werner 1994, 43-72.

$45 \mathrm{Vgl}$. Butler 1935 und die Studie „Die Querelle des Anciens et des Modernes, der Nationalismus und die deutsche Klassik“. In: Fuhrmann 1982, $129 \mathrm{ff}$. 
- Erstens galt Griechenland als die älteste, gleichsam parthenogenetisch, also aus sich selbst heraus entstandene und daher besonders reine „National"-Kultur.

- Zweitens erschien diese Kultur den Litterati als das Urbild für eine hinreichend komplexe, vor allem aber Schreiben und Leben versöhnende Schriftkultur: Der Identität von Werk und Person, für die der ,Grieche Goethe als Vorbild stand, entsprach per analogiam die zwischen Kultur und Nation.

- Drittens verlangten griechische Sprache und Literatur eine andere, von den Konventionen der lateinischen Gelehrsamkeit abweichende, wenn nicht sogar ihnen feindlich entgegengesetzte Kompetenz: Wie die Philologie über die Rhetorik, so wurde die Poesie über die Prosa und die Bildung als pseudoreligiöser „innerer Wert“ (W.v.Humboldt) über den Diskurs öffentlicher Aufklärung erhoben. ${ }^{46}$

Anders und kaum vereinbar mit der Graecomanie erscheint dem historischen Rückblick jene andere Sparte nationaler Mythopoiesis, die als Teutomanie dem Kriegsgeist opferte. Auch hier galten die Beschwörungen einem längst literarisierten, ideologisch jedoch in Naturpoesie wieder rückübersetzten Geist jener germanischen Ahnen, die die ersten Erben der klassisch-griechischen Kultur, die Römer, militärisch in die Knie gezwungen hatten. Gefragt war Poesie als Ritual und Aktion: Gesang, Tanz, Mimus. ${ }^{47}$

Das Nebeneinander der beiden zuletzt kurz skizzierten kulturellen Berufungsgeschichten scheint jener Homogenitätsvorstellung zu spotten, von der im Zusammenhang mit der Normativität der „Nationalkultur“ und „-bildung“ meist die Rede ist. Die Geschichten konvergieren indessen dort, wo Kultur und Literatur als Medien der Herrschaft auch und gerade über die andern verstanden wurden. Herder deutet diese Möglichkeit an, ohne jene aggressive Feindbildpolitik zu betreiben, die Spätere unter andern Bedingungen mit der Idee einer historischen Weltmission der „Teutschheit“ verbunden haben. ${ }^{48}$ Der mittelständische, literarisch distinguierte Nationalstolz sucht seine Lorbeern nicht primär auf dem Schlachtfeld oder in der

46 Michael Werner erklärt in einer vergleichenden Studie die Unterschiede in der literarischen Praxis Frankreichs und Deutschlands u.a. aus der Opposition zwischen Rhetorik einerseits und Philologie anderseits: La place relative du champ littéraire dans les cultures nationales. Quelques remarques à propos de l'exemple franco-allemand. In: Espagne/Werner 1994, 15-30.

47 „Der beste Gesang für unsere Nation ist unstreitig ein Bardit, den sie zur Verteidigung ihres Vaterlandes in die Schlacht singt; der beste Tanz, der sie auf die Batterie führt; und das beste Schauspiel, was ihnen hohen Mut gibt." Möser 1986, $75 \mathrm{f}$.

48 Z.B. Wachler 1818/19 pass.; Vilmar 1845; Gelzer 1847-49. S. auch Menzel in seinen Literaturgeschichten von 1836 u. 1858/59, in denen Franzosen- und Judenhaß Hand in Hand gehen; dazu Beckers Nachwort zur Ausg. von 1828 (ND 1981). 
Tagespolitik zu erwerben. Er rechnet vielmehr mit der „Jahrtausende“ währenden Herrschaft der Kultur. ${ }^{49}$

So äußert sich die in allen Zivilisationen anzutreffende Sehnsucht der Intellektuellen, Geist mit Macht zu paaren. Herder hat auch wie andere seiner literarisch produktiven Landsleute die nationale Kultur aus dem Amalgam von zwei sehr heterogenen Elementen konstruieren wollen: der „Humanität" der urbanen Kultur der Griechen und der vorzivilisatorischen Unmittelbarkeit stammesgesellschaftlicher Riten („Lieder der Wilden“). Ob das als ein Ausdruck für jene Haltung zu verstehen ist, die der moderne Sozialhistoriker „defensive Modernisierung“ (H.-U.Wehler) nennt, ist an dieser Stelle nicht zu entscheiden. Eines aber steht fest: Die Suche nach den integrativen Faktoren der nationalen Kultur blieb im 18. Jahrhundert stets teils bejahend, teils verneinend - bezogen auf die soziokulturellen Standards der Franzosen und/oder der Engländer, Standards, deren Tiefenstrukturen in jenen Traditionen zu suchen sind, die, ungeachtet nationaler Differenzen, die Rede von einer gemeinsam bewohnten Kultur rechtfertigen. Die positive Selbstdefinition - der Mechanismus wird von psychologischer Seite als Wechselspiel zwischen Auto- und Hetero-Stereotypisierung beschrieben - bedarf aber offenbar einer Antistruktur, in der die als anders, als fremd oder als feindlich eingestuften Eigenschaften, mit denen es zu konkurrieren gilt, identifiziert werden können. Schon allein der in diesem Zusammenhang vor allem von Herder favorisierte Begriff der "Nationalbildung“ weckt die Vorstellung von einer gleichartigen, einer homogenen Welt symbolischer und zugleich verpflichtender Orientierungen, die über die engen Grenzen lokaler Traditionen hinausgreifen. Nur die großen Stil- und Charakterzüge kamen für den Entwurf einer solchen, als vorbildlich weiterwirkenden Welt in Frage. Und nur die große Persönlichkeit war imstande, den aus den Nebeln der Vergangenheit wirkenden Mächten, sagen wir: des Germanischen und des Hellenischen, die Einheit eines nationalen Kulturdenkmals zu geben. Diese Persönlichkeit hatte in den Literaturgeschichten des 19. Jahrhunderts einen Namen: Goethe. Bald nach der Reichsgründung schrieb Wilhelm Scherer über ihn unter Verwendung eines längst eingefleischten Topos: „Germanische und hellenische Bildungselemente, zweierlei Stile, gewannen gleichzeitig über ihn Gewalt und befruchteten sich gegenseitig". 50

49 „Die Geschichte zeigt, daß alle herrschende Völker der Weltperioden nicht durch Waffen allein, sondern vielmehr durch Verstand, Kunst und durch eine ausgebildetere Sprache über andre Völker oft Jahrtausende hin geherrschet haben, ja daß selbst, wenn ihre politische Macht verfallen war, das ausgebildete Werkzeug ihrer Gedanken und Einrichtungen andern Nationen als ein Vorbild und Heiligtum wert geblieben." Herder, Idee, 604.

50 Scherer 1927, 488. Nach Findel $(1857,254)$ vereinigte Goethe „griechischen Geist und deutsches Gemüth". 
„Nach Goethes Beispiel (zu) leben“, schien dem Literaturhistoriker selbst Ende des 19. Jahrhunderts durchaus noch möglich und als Gegenmittel gegen drohenden Kulturzerfall empfehlenswert. Die Glaubenslehre verlangte nur eines: die „Poesie für eine heilige Angelegenheit" des deutschen „Volkes“ zu halten (Scherer 1927, 720). Man kann diese pathetische Mischung aus Kultischem und Kulturellem durchaus mit dem Willen des deutschen Bildungsbürgertums in Verbindung bringen, sich mithilfe einer zugleich ästhetisch und religiös und also rational schwer zugänglichen Selbstcharakteristik von den vermeintlich schlichteren Kulturmustern der westlichen Gesellschaften zu unterscheiden. Man sah sich selber gern als komplizierteren Charakter und verwechselte nicht selten Politik mit Kultur, was sich fatal auch nach innen auswirkte. Denn der Abwehr der westlichen, sprich: demokratischen Einflüsse entsprach in der Regel die Denunziation kulturell „fremdartiger" Gruppen im eigenen Land.

Ein Mechanismus, den ein Zeitgenosse Scherers, der nationalliberale Politiker Ludwig Bamberger, nicht zu Unrecht wie eine immer wiederkehrende sozialpsychologische Erfahrung beschrieb: Vom „Haß gegen das Fremdartige jenseits der Grenze bis zum $\mathrm{Haß}$ gegen das, was sich [...] als fremdartig in der eigenen Heimat ausfindig machen läßt, “ ist „nur ein Schritt“. Der im Bildungsbürgertum weit verbreitete Antisemitismus fand im radikalen Nationalismus eines seiner wirksamsten Rechtfertigungsmuster, oft als Ergebnis einer intoleranten, in Krisenzeiten pestartig aufbrechenden Sündenbockmentalität. Die Juden, die eine „Nation von Betrügern“ oder „von Kaufleuten" zu nennen, schon dem Philosophen Kant einerlei war, galten als nicht bildungsfähig und bar jeder „bürgerlichen Ehre“. Sie als „Fremde“ und „Ausländer“ aus der Nationalkultur auszugrenzen, weil sie durch Bildung niemals an der "geschichtlichen Gemeinsamkeit“ der Nationalsprache und daher umso viel weniger am „Volksgeist“ zu partizipieren imstande seien, war schon früh das wohlfeile Argument jener, die den Judenhaß um eines kulturellen Reinheitsprinzips willen propagierten, das, würde es wirklich befolgt, jede künstlerische Produktivität ersticken muß. ${ }^{51}$

Doch in krassem Widerspruch zu solchen Tiraden haben sich de facto wie gezeigt - die Propagandisten der "Nationalkultur“, "-literatur“ und

51 Zur Geschichte des Antisemitismus in Deutschland und seiner Verbindung mit dem Bildungsbürgertum vgl. Sterling 1969 u. Erb/Bergmann 1989. Kant, der die zit. Ausdrücke im $\S 46$ seiner Antbropologie von 1798 verwendet $(1983,136$ f.), hält die moralische Bildung der Juden (er benutzt das transitive Verb „moralisieren“) für eine „vergebliche Plane“. Bamberger zit. nach Wehler III, 1995, 929. Scherer schloß sich im Antisemitismusstreit von 1879/80 der Erklärung gegen Treitschke an, war aber dafür, "die deutschen Juden zu Deutschen zu machen“" (Scherer 1927, 520). Die letzten Zitate finden sich in Richard Wagners Pamphlet Das Judenthum in der Musik, 1850, drei Jahre vor Gobineaus Essai sur l'inégalité des races bumaines, erschienen (Wagner 1888, 66 ff.). 
"-bildung“ keineswegs allein aus dem Fundus eigener Überlieferungen bedient, ja sich mangels Masse gar nicht daraus bedienen können, sondern mit Vorliebe fremde Quellen angezapft und übersetzt. Dazu gehörte auch der aus der antiromanischen Graecomanie des späten 18. Jahrhunderts geborene Homerkult, der, blickt man allein auf Klopstocks Messias (1748-1773) und Vossens Ilias- und Odyssee-Übertragungen (1781-1793), die deutsche Literatursprache tiefgreifend verändert hat. ${ }^{52}$ Erinnert sei darüber hinaus aufs neue an die produktive Rezeption Shakespeares, aber auch des bürgerlichen Trauerspiels (Lillo, Diderot) sowie der englischen Romane (Richardson, Fielding), der skandinavischen Heldenepik und des schottischen $O s-$ sian. Klopstock und seine Jünger im Göttinger Hainbund (1772-1775) haben auf diesem Umweg der deutschen Literatur die von Möser den Nationalerziehern aufgeschwatzte patriotische Bardenmode geschenkt; Herder hat im Briefwechsel über Ossian (1773) der die zeitgenössische Zivilisation und Kunst zum Schein verleugnenden Poesie ein neuartiges, nämlich anthropologisches Fundament verschafft. Reform der Literatur, das hieß: den noch geltenden Epochenstil zerstören, indem man die Gärten fast aller greif- und übersetzbaren Überlieferungen auf der Suche nach individueller Vielfalt durchstreift. Zugleich hieß es auch: Historisierung der Tradition und - paradox genug - Verklärung der Dichterrolle im Sinne der alten vates-Funktion. So entsprach der erhofften Affizierung patriotischer Empfindungen durch das poetische Wort die Weihe priesterlicher Selbsterhöhung. Das „rasende Odengeschnaube“ (Lichtenberg) der exaltierten Poeten läßt sich vor diesem Hintergrund als ein Versuch deuten, den literarischen Patriotismus als Gegenkultur gegen die Exklusivität der Hofkultur durchzusetzen. Noch war dieser Patriotismus nicht auf eine nationale Blut-und-Boden-Opfermentalität runtergekommen, sondern der Name für eine Tugend, die zwischen neugriechischer Mäßigung und teutonischer Exaltation schwankte. Schwärmten die Hain-Bündler und Klopstockianer in höchsten lyrischen Tönen vom Patriotismus als Grundlage nationaler Freiheitsgesinnung, so mahnte die Gegenseite, vertreten durch Wieland, über Vernunfterziehung einer vaterländischen Freiheit den Weg zu bereiten, die mehr Rechte dem Geist als der Macht vindiziert. Sein Traumbild des „Nazional-Patriotismus" mußte Wieland aber wiederum mithilfe des literarischen Imaginaire ins klassische Griechenland verlegen. Denn die deutsche Realität bot in dieser von Goethe so bezeichneten "nullen Epoche“ den Schriftstellern und Dichtern ,weder Halt, Stand noch Ansehen“ ${ }^{53}$

Es ist unmöglich, die widersprüchliche Vielseitigkeit der produktiven Rezeptionsansätze in der literarischen Praxis seit der Mitte des Jahrhunderts auf einen einzigen, gar rein nationalen Nenner zu bringen. Die selbst-

52 Wohlleben 1990.

53 Wieland 1792 und 1793. Goethe BA 13, 1972, 293 u. 429. 
ernannten dröhnenden Barden z.B. waren zugleich virtuose Nachahmer, Übersetzer und Anverwandler antiker, italienischer, spanischer Formen; die Grenadiere der ,wilden' Naturpoesie zugleich Adepten des Genfer Bürgers Rousseau. Der Enthusiasmus fürs Vaterländische war noch nicht monolithisch erstarrt, hatte sich - das wilde Geschrei in einigen Hainbundgedichten beiseite gelassen - noch nicht aggressiv mit Fremden- oder gar Rassenhaß bewaffnet.

Was die zeitgenössische Formel von der Einheit in der Mannigfaltigkeit andeutet, das erscheint dem Rückblick als Signatur der Epoche. Die Soziogenese des Nationalen tendiert zur Homogeneität, da diese die Bedingung für das Bewußtsein eines jeden einzelnen bildet, eine gemeinsame Kultur zu bewohnen. Dieses Gemeinsame heißt in der Sprache der Zeit „Geist des Zeitalters" oder "Genius der Nation", und es bleibt eine zählebige, auf gesellschaftliche Integration zielende Redeweise der schriftkulturellen Experten, daß es die „Nationalliteratur“ sei, die diesen „Geist“ oder „Genius“ repräsentiere. ${ }^{54}$ Diese simplifizierende Redeweise unterstellt der Nation und ihrer Literatur einen Repräsentationsmodus, den schon der oberflächlichste Blick auf das Oeuvre des einen oder andern zum „Nationaldichter“ promovierten Autors Lügen straft. Und ist es nicht eine der folgenreichsten Einsichten der im 18. Jahrhundert begründeten Literarästhetik, daß jeder original-geniale poetische Text unvergleichlich und inkommensurabel sei? Die Antwort auf diese Problemlage kann nur lauten: Homogenisierung im Sinne der Konstruktion einer "Nationalkultur" schließt die Kommunikation mit andern Kulturen und schließt Binnendifferenzierungen nicht aus, sondern setzt sie voraus. Der Grund dafür ist simpel, denn die das Prinzip der Egalität achtende Nationwerdung nimmt ausdrücklich die besonderen kulturellen Ausdrucksformen anderer gesellschaftlicher Gruppen wahr, mit denen der Konkurrenzkampf um Einfluß- und Meinungsbildungsmonopole angesagt ist. Schließlich blieb man während des rauhesten Streits mit den Nachbarn um kulturelle Macht bzw. literarisches Ansehen sowieso im Kreis von Verwandten mit einer gemeinsamen, nämlich europäischen Vergangenheit. Kurz, der reduktive Schluß vom individuellen Werk auf das Ganze der Nation folgt einer mikrokosmischen Zuschreibungslogik, nach der die Einmaligkeit des Einzelnen als Anzeichen der gesuchten Eigentümlichkeit des Ganzen anzusehen ist. Dazu bedarf es aber - worauf Herder in einer merkwürdigen Passage zu sprechen kommt - eines besonders ,feinen', will sagen: an Zirkelschlüssen gestählten Mutes. Denn in einem solchen, übrigens eher vulgären Fall geht es ja darum, in der Nation das Subjekt jener Werke zu sehen, aus denen der Kulturphilosoph auf ihren „Charakter“

54 Zum Zusammenhang zwischen "Zeitgeist" und nationalem Denken vgl. Hinrich C.Seeba, Zeitgeist und deutscher Geist. Zur Nationalisierung der Epochentendenz um 1800. In: Fohrmann/Voßkamp 1987, 188-215. 
schließt. Nach Herder geschieht das, indem man das dem stetigen Wandel Unterworfene wie ein Zauberer zum Reden bringt:

Wie ganzen Nationen eine Sprache eigen ist, so sind ihnen auch gewisse Lieblingsgänge der Phantasie, Wendungen und Objekte der Gedanken, kurz, ein Genius eigen, der sich, unbeschadet jeder einzelnen Verschiedenheit, in den beliebtesten Werken ihres Geistes und Herzens ausdruckt. Sie in diesem angenehmen Irrgarten zu belauschen, den Proteus zu fesseln und redend zu machen, den man gewöhnlich Nationalcharakter nennt und der sich gewiß nicht weniger in Schriften als in Gebräuchen und Handlungen der Nation äußert: dies ist eine hohe und feine Philosophie. (Herder, BBH II, 64)

Es ist nach dieser hellsichtigen Andeutung eine Logik des Zuschreibens, die darüber entscheidet, wie national bzw. nationalcharakteristisch eine Literatur aussehen darf oder soll. Unter Anwendung eben derselben Logik läßt sich jedoch auch ein anderes, den Erfahrungen näher verwandtes Muster entdecken: der in gemeinsamen, griechisch-römischen und jüdisch-christlichen Traditionen enthaltene Pluralismus, vor dessen vitaler Fülle das mächtig sich aufspreizende Gebot kultureller Reinheit/Einheit wie eine dürre Karikatur jener Integrationspolitik erscheint, die dem Biedersinn des redlichen, mit preußischen Tugenden gefütterten Bürgers entsprach.

\section{Die Geschichte der „Nationalliteratur“ ist die „Familiengeschichte“ des Bildungsbürgertums}

Die letzten Jahrzehnte des 18. Jahrhunderts bastelten noch am Kanon der deutschen Literatur. Mancherlei Bizarrerien geben Auskunft darüber, daß eine "Nationalliteratur" im bibliographischen Sinn der Kanonbildung noch gar nicht existierte. Der Heroenkult der Hainbündler machte z. B. keinen Unterschied zwischen Klopstock, Cato, Hermann, Brutus und Tell. Vielleicht paßte das ja zu den synkretistischen Neigungen dieser Gruppe, deren Studien und Texte jedenfalls besonders deutlich die damals geläufige Formel belegen, die deutsche Literatur käme erst dann zu sich selbst, wenn es ihr gelänge, von der „Nachahmung andrer Nationen“ zur „Nacheiferung " mit diesen zu wechseln. ${ }^{55}$ Der Ausdruck „Bildung“, der gern als Kennwort für eine deutsche Sonderentwicklung betrachtet wird, schließt ebenso wenig das Nachahmen aus wie dieses die Mimesis, d.i. die kreative Transformation vorgefundener Formen und Materialien, wo auch immer sie herkommen mögen. Daß der Held Hermann, nicht zuletzt dank der seit Huttens Arminius (1529) nicht mehr erlahmenden Wiederbelebungsversu-

55 Herder, Idee, 606. 
che, noch Jahrhunderte später als monumentales Vorbild für die literarische Bildung der Deutschen gefeiert wird, gehört allerdings zu den eher schrulligen Seiten einer nationalistisch orientierten imitatio-aemulatioEmpfehlung. Der „allgemeine deutsche Bildungsgang“, schreibt um die Mitte des 19. Jahrhunderts Karl Rosenkranz, beruhe darauf, daß die Deutschen vom „Fremden“ lernen „wie Arminius zwar selbst die Schule römischer Kriegskunst durchmachte, aber um die Römer zu schlagen“. Wenn ein Germanist des Kaiserreiches 30 Jahre später die „Nationalliteratur" auf den geistigen Freihandel mit dem Ausland verweist und über das Auf und Ab von "Großmächten" in den Literaturen spricht, so geschieht das mit dem patriotischen Stolz, der den Erfolg der von Rosenkranz beschriebenen Taktik voraussetzen konnte. ${ }^{56}$ Der deutsche Schulmeister, hieß es nach 1870 in Frankreich, habe bei Sedan gesiegt.

Wer mit Ursache und Wirkung in der Geschichtsschreibung rechnet, kommt ganz auf seine Kosten, wenn er die Entstehung des deutschen Nationalismus als Massenbewegung aus der postrevolutionären Reichsauflösung, den Erfolgen und Niederlagen der napoleonischen Kriegszüge und den seitdem anhaltenden propagandistischen sowie militärischen Auseinandersetzungen mit dem westlichen Nachbarn erklärt. 1806 militärischer Sieg des Französischen Heeres über Preußen ..., 1870 Sieg der Preußen über die Franzosen ... - im einen wie andern Fall rührten beide Ereignisse mächtig an die Fundamente des kulturellen Selbstverständnisses in der einen wie andern Gesellschaft. Die Fundamente selbst aber werden in solchen epochalen Erfahrungssituationen nicht kurzfristig ab- und umgebaut, wie stark auch immer sich einzelne ihrer Elemente verschieben. Aus dem Blickwinkel der longue durée betrachtet, bleiben alte, in Latenz liegende Prägungen Denkmuster und Ressentiments - virulent und trotzen dem Erfahrungswandel wie der Vorurteilskritik. Mit wachsender Konfliktbereitschaft und durch zackige Außenpolitik kompensiertem Krisenmanagement im Innern nehmen die Spannungen zwischen Nachbarn vielmehr zu. Nationalistischer Fundamentalismus auf beiden Seiten ist die Folge, der Kampf mit Worten wird fanatisch, der Fanatismus handgreiflich. Hier finden nicht nur die Zeitungsideologen und Kriegspropagandisten Arbeit, auch der Geschichtsschreiber sieht sich herausgefordert, seine Erzählungen auf der Basis nationaler Großtaten zu reorganisieren.

56 Rosenkranz zit. nach Jürgen Fohrmann, Deutsche Literaturgeschichte und historisches Projekt in der ersten Hälfte des 19. Jahrhunderts. In: Fohrmann/Voßkamp 1991, 212. Fohrmann kommentiert (ebd.): „Der Auswicklungsprozeß der deutschen Poesie endet damit in der Vereinnahmung der anderen Nationalliteraturen als triumphale Heimkehr und begründet die besondere Stellung der Deutschen als Kulturnation der Gegenwart“. Der Germanist des Kaiserreichs ist Erich Schmidt, der in seiner Berliner Antrittsvorlesung von 1880 über "Wege und Ziele der deutschen Literaturgeschichte“ sprach; zit. nach Marsch 1975, 414. 
$\mathrm{Zu}$ den heroischen Daten der deutschen Militär- und gleichzeitigen Kultur- sowie Dichtungsgeschichte gehören, glaubt man den professionellen Geschichtenerzählern, die Konflikte mit den Franzosen: Mit dem Siebenjährigen Krieg und der Niederlage der Franzosen bei Roßbach (1757) fällt die Geburt der modernen deutschen Literatur in den Werken Lessings und Klopstocks zusammen. Der „Befreiungskrieg“ von 1812/13 zählt nicht nur zu den Gründungsdaten politischer, sondern auch kultureller Wiedergeburtsphantasien, die während der restaurativen Folgeperiode in nationalfanatische Exzesse umschlagen werden. An die pietistisch-moralistischen Parolen, an die antifranzösischen und antisemitischen Haßtiraden der Jahn, Arndt, Müller, Menzel konnte in späteren Konfliktsituationen immer wieder angeknüpft werden. Dann 1840: Die von der französischen Regierung säbelrasselnd vom Zaun gebrochene Rheinkrise hat den Deutschen nicht nur einige ihrer populärsten Rheinlieder und Hoffmann von Fallerslebens Deutschlandlied - die spätere Nationalhymne - eingebracht. Sie hat auch - wie manche andere Bedrohung von außen - den Nationalgedanken zum Massenwahn werden lassen. Schließlich 1870/71: Die Reichsgründung unter preußischen, über Frankreich triumphierenden Fanfaren löst eine wahre Flut von nationalen Literaturgeschichten aus, die nichts anderes wollten, als den Weg des "deutschen Geistes“, soweit dieser sich des Buchstabens bedient hat, bis zur Ankunft im Gelobten Land des Kaiserreichs nachkonstruieren. Den roten Faden in diesen mit steigendem Blutverlust verbundenen Fortsetzungsgeschichten bildet der Parallelismus zwischen antifranzösischer Zivilisationskritik und deutscher Kulturüberlegenheit. Ein altes und lange Zeit nachwirkendes Syndrom, über das 1841 ein berühmter Internationalist in einem Rückblick schrieb, diese „Einseitigkeit machte denn die Deutschen zum auserwählten Volk Israel und mißkannte alle die zahllosen weltgeschichtlichen Keime, die außerdeutschem Boden entsproßt waren". 57

In Deutschland lebte und webte der Mythos von der Poesie als einer primordialen (Natur-)Kraft der Kultur, d. h. nicht zuletzt der Nationalsprache und -literatur. Und das war für die meisten Autoren ein hinreichendes Kriterium, nicht nur Differenz und Gegensatz zwischen dem französischen und dem deutschen "Geist" zu behaupten, sondern auch entsprechende Überlegenheitsphantasien zu kultivieren. Denn Poesie, das war mehr als Literatur, mehr als ästhetischer Formkult; sie galt - um ein Wort Wilhelm von Humboldts zu zitieren - als eine „Macht“, die wie „Sittenlehre und Reli-

57 Der Text fährt fort: „Namentlich gegen die Franzosen, [...] deren Hegemonie in Äußerlichkeiten darin ihren Grund hat, daß sie die Form der europäischen Bildung, die Zivilisation, jedenfalls von allen Völkern am leichtesten beherrschen, [...] wandte sich der bilderstürmende Grimm am meisten“. Friedrich Engels zit. nach J.J.Müller $1974,81$. 
gion selbst“ die "moralische Bildung" des Menschen beeinflußt. ${ }^{58} \mathrm{Um}$ ein anderes prominentes Beispiel für diesen „Kultus der Poesie“ (W.Scherer) zu nennen: Grimms Vorrede zum 1854 erschienenen ersten Band des Nationalwörterbuchs hielt immer noch Sprache und Literatur für das Palladium deutscher Gemeinsamkeit und beschwor emphatisch die rational nicht nachvollziehbare "gewalt der poesie“" als Quellgrund für die eigene Spracharbeit. ${ }^{59}$ Man darf sich hier vielleicht fragen, ob der Philolog mit der „gewalt" auf den griechischen Orpheus- oder auf den germanischen Bardenmythos anspielen wollte.

Wenn die Deutsche Philologie eine „Tochter des nationalen Enthusiasmus" ist ${ }^{60}$, dann gilt diese von einem Unverdächtigen ausgesprochene Anspielung auf die politische Schwärmerei als eine der Säulen der Germanistik zweifellos für den größten Teil ihrer Gründerväter. Natürlich sind hier Differenzierungen denkbar, da das rhetorische Spektrum von der obrigkeitshörigen Predigt à la Ludwig Wachler, über die antifeudale Auflehnung im Vormärz bis zur staatstragenden Affirmation nach der Reichsgründung reicht. ${ }^{61}$ Was immer aber die verschiedenen Haltungen verbindet, es gibt dafür keinen besseren Ausdruck als den der Schwärmerei. Denn das Vorhaben, die Genese der „Nationalliteratur" in ihrem Zusammenhange zu erzählen, hat - genau genommen - kein konkretes Objekt. Die Erzählung bringt dieses vielmehr erst hervor. Sie allein ist die Garantie dafür, daß der subjektive Willensakt, den der Satz „Eine Nationalliteratur soll sein!“ ausdrückt, sich in einem erzählenden Text objektiviert und - so die Hoffnung der literarischen Nationalerzieher - das Publikum von Wert und Größe der vom Faden der Erzählung zusammengehaltenen Autoren und Werke überzeugt. Wenn der Begriff der „Nationalliteratur“ überhaupt die normative Bedeutung gewinnen sollte, die ihm die Vertreter der literarischen Bildungsreligion mit beschwörenden Worten zugesprochen hatten, so hing das nicht von den Dichtern, sondern von den Vermittlern und deren publikumswirksamer narrativer Rhetorik ab. Denn es waren nun einmal die Literaturgeschichten, die den Anspruch erhoben, die „innere“, also unsichtbare Geschichte der Nation erzählend zu gestalten, ohne dem empirischen Pendant der „äußeren“, d.i. soziopolitischen Bedingungen besondere Aufmerksamkeit widmen zu müssen. Die Weite des zugrundeliegenden Litera-

\footnotetext{
Humboldt 1960, $562 \mathrm{ff}$.

Grimm 1854, XXXVI.

Wilhelm Scherer, Wissenschaftliche Pflichten. In: Euphorion 1, 1894, 1.

1 Vgl. Wachlers im Namen der altständischen Ordnung geführte Polemik gegen die Frz. Revolution (1818/19, II.316ff.). Zur antifeudalen Einstellung vgl. Jörg Jochen Müller, Germanistik - eine Form bürgerlicher Opposition. In: J. J. Müller 1974, 5 ff. Über die staatstragenden Tendenzen der nach 1870/71 erschienen Literaturgeschichten siehe Andreas Schumann, Glorifizierung und Enttäuschung. Die Reichsgründung in der Bewertung der Literaturgeschichtsschreibung. In: Amann/Wagner 1996, $31 \mathrm{ff}$.
} 
turbegriffs entsprach - selbst wenn im Titel von „Dichtung“ die Rede war in etwa der Schlegelschen Paraphrase: „Inbegriff aller intellektuellen Fähigkeiten und Hervorbringungen einer Nation" " 62

Was nun Zusammenhang, Kontinuität, Fortschritt oder Finalität in den Erzählungen der einzelnen Literaturgeschichten bedeutete, wurde von den Vorstellungen gesteuert, die sich der jeweilige Historiker über Wert und Unwert der ins lebendige Gedächtnis zu rettenden Autoren und Werke machte, um einen verbindlichen, in die allgemeine Schulbildung zu importierenden nationalen Literaturkanon konstruieren zu können. Der Parallelismus zwischen militärisch-politischen Erfolgen und literarischen Initiativen blieb ein beliebtes Muster und konnte, je nach Absichten und Fähigkeiten des Erzählers, auf der diachronen Achse mit dem Muster eines zwangsläufigen, kontingente Faktoren ausschließenden Prädestinationsgeschicks verbunden werden. ${ }^{63}$

Der Historisierung literarischen Wissens lagen indessen nicht nur ideologische Motive zugrunde. Im späten 18. Jahrhundert zerfielen bekanntlich die bis dahin geltenden klassischen Regelkonventionen und -prinzipien der ästhetischen Produktion und Kritik; sie erschienen dem von beschleunigten Zeiterfahrungen sensibilisierten Expertenbewußtsein als relative, d.h. zeitlich bedingte Größen. Den normativen ethico-ästhetischen Gehalt der Werke vor diesem Relativismus zu schützen, konnte daher nur gelingen, wenn sich der universelle, maßstabsetzende Wert der ausgewählten Werke als dauerhafte Größe aus dem diachron entfalteten Literaturprozeß heraushob. Historisierung und Ästhetisierung stehen als Formen wissenschaftlicher, sprich: philosophischer Reflexion in einer korrelativen Beziehung. Friedrich Schlegel bringt das damit angesprochene Reflexivwerden literarischer Traditionen zum Ausdruck, da er einerseits die Poesie als eine Form der „National-Erinnerung“, anderseits die Geschichtsschreibung als eine Gestalt des nationalen „Selbstbewußtseins“ zugleich unterscheidet und aufeinander bezieht. ${ }^{64}$

Diesen Gedanken variierend, läßt sich die bis ins letzte Drittel des 19. Jahrhunderts gepflegte Geschichtsschreibung der Nationalliteraturen als

62 Gervinus Bd.V., 1874, 286, A.81; vgl. auch Rinne 1842/43. Friedrich Schlegel, Geschichte der alten und neuen Literatur [1815]. KA VI, 1961, 15.

63 Vgl. z.B. folgende mit Versprechen (Prophezeiung) und Erfüllung arbeitende Passage: „Goethe forderte, was sich schon bei seinen Lebzeiten zu erfüllen begann und vor unseren Augen immer noch mehr und vielleicht schon zu viel erfüllt. Die kurze poetische Blütezeit, wie sie durch die Taten Friedrichs des Großen gefördert wurde, enthielt eine Prophezeiung auf neue Taten. Die Freude an seinen Dichtern gab einem zerrissenen Volke den einzigen gemeinsamen Besitz, in dem es sich stolz und kräftig fühlte. Die Dichter selbst erinnerten an vergangene Tage politischer Größe. Das Nationalbewußtsein erstarkte; und was eben noch ein phantastischer Wunsch zu sein schien, ward beglückende Wahrheit". Scherer 1927, 719.

64 Schlegel KA VI, 1961, $16 \mathrm{f}$. 
ein Versuch verstehen, auf der Basis akademischer Studien ein Pantheon der nationalen Gedächtniskultur zu errichten, in dem wie in der Walhalla Besonderheit und Inkommensurabilität des einzelnen in der epigonalen Einheitskonstruktion einer nationalen Kultstätte aufgehoben wurden. Zwei Voraussetzungen durften zu diesem Zweck nicht in Frage gestellt werden: der Glaube an die quasi religiöse Bildungsmächtigkeit der Literatur, vorab der Poesie, und der an die Formbarkeit des Publikums. Wurde der erstgenannte Glaubenssatz von der langsam sich durchsetzenden Professionalisierung der germanistischen Philologie ausgehöhlt, so hat der zweite über die Allgemeine Schulpflicht und die Lehrpläne der Höheren Schulen ein pädagogisch eingehegtes Wirkungsfeld für nationalliterarische Sozialisationskampagnen gefunden, das allerdings bald von den Predigern völkischer Intoleranz besetzt worden ist.

Wer die oft in Bänden sich auswälzenden Geschichten der Nationalliteratur bzw. der Nationalkultur erzählte, schrieb nicht bloß für die Berufskollegen in Schule und Universität. Der geschätzte Adressat war vielmehr oft genug jener staatstragende, konservative, aber reformwillige Bildungsbürger, dessen Vorstellungs- und Wertewelt der Literaturhistoriker teilte. Literaturgeschichte gehörte, wie die der Künste und Wissenschaften, zur „Familiengeschichte" des Bildungsbürgertums. ${ }^{65}$ Auch hier gab es natürlich wie in jeder Familie diese und jene Physiognomie: Der Aktivist verkündete mit der „Vollendung“ der literarischen Persönlichkeitsbildung den Beginn politischer Umwälzungen; der passive Frömmler schrieb seine Literaturgeschichte als nationalreligiöses Erbauungsbuch, sprach vom „Himmel der Literatur" und empfahl seinen Lesern, zu den "Classikern als zu Höheren auf[zu]schauen".66

Die teils propagandistische, teils pädagogische Arbeit der literarischen Bildung via Historie ließ sich, selbst unter den Augen wissenschaftsstrenger Prinzipienwächter, meist mühelos mit weltanschaulichen Irrtümern diverser Schattierungen verbinden, die das ganze Farbenspektrum von der rückwärts gewandten politischen Romantik der Schlegel, Tieck, Arnim, Novalis über die liberalkonservative Position eines Gervinus, eines Hettner und frühen Menzel bis zu den klerikal-obskurantistischen Erzählungen der Gelzer und Vilmar abdecken konnten. Immerhin, die traditionsbildenden Literaturgeschichten des 19. Jahrhunderts - die Bücher der Schlegel, Gervinus, Hettner und Scherer - haben sich von der Muse der Nationalbildung nicht zu nationalistischer Engstirnigkeit verführen lassen. Sie haben den Eigenheiten der andern, zumal der englischen und französischen Schriftsteller,

65 Freytag $1928,320$.

66 „Der Wettkampf der Kunst ist vollendet“, schrieb Gervinus um 1870 unter Bezugnahme auf die Goethezeit $(1874,816)$. Findel 1857, 12. 
zumindest die Achtbarkeit konkurrenzfähiger Rivalen zugestanden und manches ihrer Produkte wohl auch studiert.

Nationalbildung blieb bis weit über 1871 hinaus eine permanente Aufgabe, die literarhistorische Erzählung vom Werden der Literaturnation wurde bald ein von völkischen "Geistesgeschichtlern" und intoleranten „Deutschkundlern“ usurpiertes Geschäft. Das Projekt „Weltliteratur" verschwand hinter akademischen Phrasen oder verlor sich in religiöse Trance, während die zeitgenössische Literaturproduktion ihren Ort in der europäischen Moderne suchte. Die oppositionelle, gegen das Ancien Régime gerichtete Unruhe der in der zweiten Hälfte des 18. Jahrhunderts einsetzenden Nationalbewegung war nach etlichen Schwächeperioden mit dem Jahr 1871 endgültig zur Ruhe gekommen. Die Literaturhistoriker zogen Bilanz. Zwischen 1871 und 1881 erschienen nicht weniger als 184 Gesamtdarstellungen der deutschen Literaturgeschichte (darunter 50 Erstauflagen). Die in diesen Büchern vorherrschende Tendenz war affirmativ: Bestätigung des „kleindeutsch-preußisch-protestantischen“ Gangs zum Altar der Nation. Doch der neue „Reichsnationalismus“ zeigte ein anderes, ein militaristisch verhärtetes und daher literaturabgewandtes Gesicht. Die Durchsetzung preußischer Tugenden bedurfte der kulturellen oder gar literarischen Legitimation nicht mehr. Es nahte "die Zeit des fernsten Abstands zwischen beiden, Literatur und Nation". ${ }^{67}$

\section{Literatur}

\subsection{Quellen}

Cohn, Gustav, Grundlegung der Nationaloekonomie. Stuttgart 1885.

Curtius, Ernst Robert, Europäische Literatur und Lateinisches Mittelalter. Bern 1948.

Danzel, Theodor Wilhelm, Zur Literatur und Philosophie der Goethezeit. Gesammelte Aufsätze zur Literaturwissenschaft. Neu hrsg. v. Hans Mayer. Stuttgart 1962.

Enzensberger, Hans Magnus, Einzelheiten II. Poesie und Politik. Frankfurt a.M. 1963.

Ernst, Fritz, Späte Essais. Zürich 1963.

Fichte, Johann Gottlieb, Reden an die deutsche Nation [1808]. In: Ausgewählte Werke, Bd. 5. Hrsg. v. F. Medicus. Darmstadt 1962.

Findel, J. G., Die classische Periode der deutschen Nationalliteratur im achtzehnten Jahrhundert, in einer Reihe von Vorlesungen dargestellt. Leipzig 1857.

67 Schumann, Glorifizierung und Enttäuschung. In: Amann/Wagner 1996, 31 u. 40. Otto Flake, Forum Germanicum. In: Das neue Magazin für Literatur, Kunst und soziales Leben 73, 1904, 576. Zum Wandel der Nationalbewegung und zur „politischen Religion“ des reichsdeutschen Nationalismus vgl. Wehler III, 1995, $938 \mathrm{ff}$. 
Freytag, Gustav, Vermischte Aufsätze aus den Jahren 1848-1894. Hrsg v. E. Elster, 1. Bd. Berlin 1901.

-, Gesammelte Werke II. Serie VII/4: Bilder aus der deutschen Vergangenheit. Leipzig 1928.

Fricke, Gerhard, Franz Koch u. Klemens Lugowski (Hrsg.), Von deutscher Art in Sprache und Dichtung. 5 Bde. Stuttgart, Berlin 1941.

Gelzer, Heinrich, Die neuere Deutsche National-Literatur nach ihren ethischen und religiösen Gesichtspunkten. 2 Bde. Leipzig 1847-49.

Gervinus, Georg Gottfried, Geschichte der Deutschen Dichtung. 5 Bde. 5. Aufl. Hrsg. v. K. Bartsch. Leipzig 1874.

-, Schriften zur Literatur. Hrsg. v. Gotthard Erler. Berlin 1962.

Goethe, BA = Berliner Ausgabe. 21 Bde. Berlin, Weimar 1972-1977.

Grimm, Jacob, Vorrede. In: Deutsches Wörterbuch. Bd.1. Leipzig 1854, I-LXVIII.

Heine, Heinrich, Historisch-kritische Gesamtausgabe. Hrsg. v. M. Windfuhr. Bd.8/I. Hamburg 1979.

Herder, Johann Gottfried, Idee = Idee zum ersten patriotischen Institut für den Allgemeingeist Deutschlands. In: SW = Sämtliche Werke. Hrsg. v. B. Suphan. Bd.XVI. Berlin 1887.

-, BBH = Briefe zur Beförderung der Humanität. 2 Bde. Berlin, Weimar 1971.

Herder, Goethe, Frisi, Möser, Von deutscher Art und Kunst. Einige fliegende Blätter. Hamburg 1773. Neuaufl. hrsg. v. Dietrich Irmscher. Stuttgart 1968.

Hettner, Hermann, Geschichte der deutschen Literatur im 18. Jahrhundert (1862-1870). 2 Bde. Hrsg. v. G. Erler. 2. Aufl. Berlin, Weimar 1979.

-, Schriften zur Literatur. Hrsg. v. J. Jahn. Berlin 1959.

Humboldt, Wilhelm von, Werke. Hrsg. v. A. Flitner u. K. Giel. Bd. I: Schriften zur Anthropologie und Geschichte. Darmstadt 1960.

Jahn, Friedrich Ludwig, Werke. Hrsg. v. C. Euler. Bd.I. Hof 1884.

Jahrbuch der Deutschen Akademie für Sprache und Dichtung. 1980/1.

Kant Immanuel, Anthropologie in pragmatischer Absicht [1798]. Hrsg. v. W. Becker. Stuttgart 1983.

Lempicki, Sigmund von, Geschichte der deutschen Literaturwissenschaft bis zum Ende des 18. Jahrhunderts. Göttingen 1920. 2. Aufl. Göttingen 1968.

Lessing, Gotthold Ephraim, Werke. Hrsg. v. H. G. Göpfert. Bd. 4. München 1973.

List, Friedrich, Das nationale System der Politischen Oekonomie. Stuttgart, Tübingen 1841.

Luftfracht. Internationale Poesie 1940-1990. Hrsg. v. H. Hartung. Frankfurt a. M. 1991.

Marsch, Edgar (Hrsg.), Über Literaturgeschichtsschreibung. Die historisierende Methode des 19. Jahrhunderts in Programm und Kritik. Darmstadt 1975 (Wege der Forschung, Bd. CCCLXXXII).

Marx, Karl, Die Frühschriften. Hrsg. v. S. Landshut. Stuttgart 1964.

Meister, Leonhard, Beyträge zur Geschichte der teutschen Sprache und National-Litteratur [Neuaufl. d. Ausg. v. 1777]. Heydelberg 1780.

Menzel, Wolfgang, Die deutsche Literatur. Stuttgart 1981.

Möser, Justus, Über die deutsche Sprache und Literatur (1781). In: Sämtliche Werke. Bd.3. Osnabrück 1986, 71-90.

Reiß, Gunter (Hrsg.), Materialien zur Ideologiegeschichte der deutschen Literaturwissenschaft. Bd. 1: Von Scherer bis zum Ersten Weltkrieg. Bd. 2: Vom Ersten Weltkrieg bis 1945. Tübingen 1973.

Rinne, Friedrich, Innere Geschichte der Entwicklung der deutschen National-Litteratur. 2 Bde. Leipzig 1842/43.

Scherer, Wilhelm, Geschichte der deutschen Literatur [1883]. 16. Aufl. Berlin 1927.

Schiller, Friedrich, SW = Sämtliche Werke. Hrsg. v. G. Fricke u. H. G. Göpfert. München 1959. 
Schlegel, Friedrich, Wissenschaft der europäischen Literatur. In: KA = Kritische Ausgabe seiner Werke. 11. Bd. Hrsg. v. E. Behler. München, Paderborn, Wien 1958.

-, KA $=$ Kritische Ausgabe seiner Werke. 2. Bd. Hrsg. v. H. Eichner. München, Paderborn, Wien 1967.

-, Aufsätze in der Europa [1803]. In: KA=Kritische Ausgabe seiner Werke. 3. Bd.: Charakteristiken und Kritiken II. Hrsg. v. H. Eichner. München, Paderborn, Wien 1975.

Strich, Fritz, Goethe und die Weltliteratur. Bern 1946.

Vilmar, August F. Christian, Geschichte der deutschen Nationalliteratur. Marburg 1845.

Wachler, Ludwig, Vorlesungen über die Geschichte der teutschen Nationallitteratur, 1. und 2. Theil. Frankfurt a. M. 1818 u. 1819.

Wagner, Richard, Gesammelte Schriften und Dichtungen. 2. Aufl. 5. Bd. Leipzig 1888.

Weltliteratur. Die Lust am Übersetzen im Jahrhundert Goethes. Hrsg. v. B. Zeller. München 1982 (Marbacher Kataloge 37).

Wieland, Christoph Martin, Sendschreiben des Herausgebers des TM an Herrn P.** zu ****. In: Der Neue Teutsche Merkur. Januar 1792, 64-112.

-, Über teutschen Patriotismus. Betrachtungen, Fragen und Zweifel. In: Der Neue Teutsche Merkur. Mai 1793, 3-12.

\subsection{Forschungsliteratur}

Almog, Shmuel, Nationalism and Antisemitism in Modern Europe 1815-1945. London 1990.

Amann, Klaus u. Karl Wagner (Hrsg.), Literatur und Nation. Die Gründung des Deutschen Reiches 1871 in der deutschsprachigen Literatur. Wien, Köln, Weimar 1996 (Literatur in der Geschichte / Geschichte in der Literatur, Bd. 36).

Anderson, Benedict, Imagined Communities. Reflections on the Origin and Spread of Nationalism. London 1983.

Barner, Wilfried u. Christoph König (Hrsg.), Zeitenwechsel. Germanistische Literaturwissenschaft vor und nach 1945. Frankfurt a. M. 1996.

Becker, Eva D., Literarisches Leben. Umschreibungen der Literaturgeschichte. St. Ingbert 1994 (Saarbrücker Beiträge zur Literaturwissenschaft, Bd. 45).

Bhaba, Homi K. (Hrsg.), Nation and Narration. London, New York 1990.

Boden, Petra u. Holger Dainat (Hrsg.), Atta Troll tanzt noch. Selbstbesichtigungen der literaturwissenschaftlichen Germanistik im 20. Jahrhundert. Berlin 1997.

Brauneck, Manfred, Die Welt als Bühne. Geschichte des europäischen Theaters. 2. Bd. Stuttgart 1996.

Butler, Eliza Marian, The Tyranny of Greece over Germany. Cambridge 1935.

Dumont, Louis, German Ideology. From France to Germany and Back. Chicago, London 1994.

Elias, Norbert, Über den Prozeß der Zivilisation. Soziogenetische und psychogenetische Untersuchungen. 2 Bde. Frankfurt a. M. 1976.

Engelsing, Rolf, Analphabetentum und Lektüre. Zur Sozialgeschichte des Lesens in Deutschland zwischen feudaler und industrieller Gesellschaft. Stuttgart 1973.

Erb, Rainer u. Werner Bergmann, Die Nachtseite der Judenemanzipation. Der Widerstand gegen die Integration der Juden in Deutschland, 1780-1860. Berlin 1989.

Eriksen, Thomas Hylland, Ethnicity and Nationalism. Anthropological Perspectives. London 1993.

Espagne, Michel u. Michael Werner (Hrsg.), Qu'est-ce qu'une littérature nationale? Approches pour une théorie interculturelle du champ littéraire. Paris 1994 (Philologiques III).

Fischer, Bernd, Das Eigene und das Eigentliche: Klopstock, Herder, Fichte, Kleist. Epi- 
soden aus der Konstruktionsgeschichte nationaler Intentionalitäten. Berlin 1995 (Philologische Studien und Quellen, H. 135).

Fohrmann, Jürgen u. Wilhelm Voßkamp (Hrsg.), Von der gelehrten zur disziplinären Gemeinschaft. Stuttgart 1987 (Sonderheft der DVjs).

-, Das Projekt der deutschen Literaturgeschichte. Entstehung und Scheitern einer nationalen Poesiegeschichtsschreibung zwischen Humanismus und Deutschem Kaiserreich. Stuttgart 1989.

- u. Wilhelm Voßkamp (Hrsg.), Studien zur Entstehungsgeschichte der deutschen Literaturwissenschaft. München 1991.

Fuhrmann, Manfred, Brechungen. Wirkungsgeschichtliche Studien zur antik-europäischen Bildungstradition. Stuttgart 1982.

Gellner, Ernest, Nations and Nationalism. Oxford 1983.

Geschichtliche Grundbegriffe. Historisches Lexikon zur politisch-sozialen Sprache in Deutschland. Hrsg. v. O. Brunner, W. Conze u. R. Koselleck. 7 Bde. Stuttgart 1972-1992.

Gessinger, Joachim, Sprache und Bürgertum. Sozialgeschichte sprachlicher Verkehrsformen im Deutschland des 18. Jahrhunderts. Stuttgart 1980.

Giesen, Bernhard (Hrsg.), Nationale und kulturelle Identität. Studien zur Entwicklung des kollektiven Bewußtseins in der Neuzeit. Frankfurt a. M. 1991.

Greenfeld, Liah, Nationalism. Five Roads to Modernity. Cambridge/Mass., London 1993.

Hobsbawm, Eric, Nationen und Nationalismus. Mythos und Realität seit 1780. München 1996.

Jusdanis, Gregory, Belated Modernity and Aesthetic Culture. Inventing National Literature. Minneapolis, Oxford 1991 (Theory and History of Literature, Vol. 81).

Kloft, Hans, Die Germania des Tacitus und das Problem eines deutschen Nationalbewußtseins. In: Archiv für Kulturgeschichte 72, 1990, 93-114.

König, Christoph u. Eberhard Lämmert (Hrsg.), Literaturwissenschaft und Geistesgeschichte 1910 bis 1925. Frankfurt a. M. 1993.

Lele, Pascal, Littérature et construction groupale ou nationale: Perspectives psychosociologiques et littératures des sociétés en développement. In: Littérature comparée / Littérature mondiale. Hrsg. v. G. Gillespie. New York, Bern, Frankfurt, Paris 1991, 109-126 (Actes du XIème Congrès de l'Association Internationale de Littérature Comparée, Paris 1985).

Low, Alfred D., Jews in the Eyes of Germans: From the Enlightenment to Imperial Germany. Philadelphia 1979.

Mennemeier, Franz Norbert u. Conrad Wiedemann (Hrsg.), Deutsche Literatur in der Weltliteratur. Kulturnation statt politischer Nation? Tübingen 1986 (Akten des VII. Internationalen Germanisten-Kongresses Göttingen 1985, Bd. 9).

Müller, Jörg Jochen (Hrsg.), Germanistik und deutsche Nation 1806-1848. Zur Konstitution bürgerlichen Bewußtseins. Stuttgart 1974 (Literaturwissenschaft und Sozialwissenschaften 2).

Quattrocchi, Luigi, Il mito di Arminio. Da Hutten a Lohenstein. Napoli 1979.

Rosenberg, Rainer, Zehn Kapitel zur Geschichte der Germanistik. Literaturgeschichtsschreibung. Berlin 1981.

Schmeling, Manfred (Hrsg.), Weltliteratur heute. Konzepte und Perspektiven. Würzburg 1995 (Saarbrücker Beiträge zur Vergleichenden Literatur- und Kulturwissenschaft, Bd. 1).

Schumann, Andreas, Bibliographie zur deutschsprachigen Literaturgeschichtsschreibung 1827-1945. München, New Providence, London, Paris 1994.

Sterling, Eleonore, Judenhaß. Die Anfänge des politischen Antisemitismus in Deutschland (1815-1850). Frankfurt a. M. 1969. 
Vierhaus, Rudolf, Deutschland im 18. Jahrhundert. Göttingen 1987.

Wehler, Hans-Ulrich, Deutsche Gesellschaftsgeschichte I: Vom Feudalismus des Alten Reiches bis zur Defensiven Modernisierung der Reformära 1700-1815. München 1987. II: Von der Reformära bis zur industriellen und politischen „Deutschen Doppelrevolution“ 1815-1845/49. München 1987. III: Von der „Deutschen Doppelrevolution“ bis zum Ende des Ersten Weltkrieges 1849-1918. München 1995.

Weimar, Klaus, Geschichte der deutschen Literaturwissenschaft bis zum Ende des 19. Jahrhunderts. München 1989.

Wohlleben, Joachim, Die Sonne Homers. Zehn Kapitel deutscher Homerbegeisterung, von Winckelmann bis Schliemann. Göttingen 1990. 